23.1

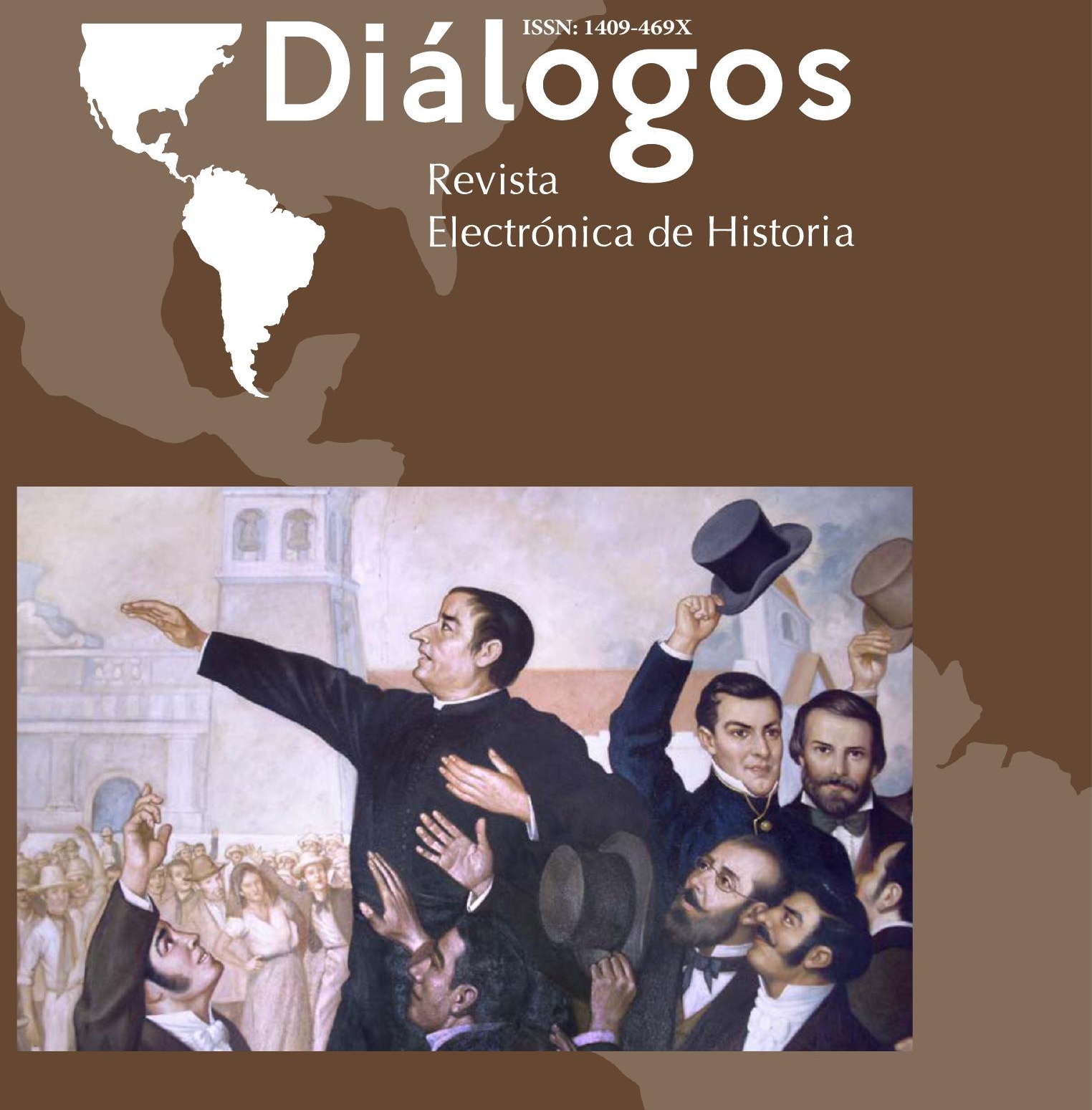

Centro de Investigaciones Históricas de América Central. Universidad de Costa Rica

\title{
Enero-junio 2022
}

url: http://revistas.ucr.ac.cr/index.php/dialogos/index 


\title{
“EL GOZE DE LOS DERECHOS DE CIUDADANO”: ELECCIONES Y CIUDADANÍA EN AMÉRICA CENTRAL, CA. 1770-1850
}

Jordana Dym

\begin{abstract}
Resumen
Entre 1808 y 1850, las provincias y luego los estados independientes centroamericanos organizaron centenares de elecciones. Este artículo examina las constituciones y reglamentos electorales para entender la teoría electoral. Ponen en en conversación esas constituciones y reglamentos con los libros de elecciones, listados de votantes, periódicos, correspondencia, y otros documentos que revelan las prácticas a nivel municipal, estatal, y federal. El análisis muestra que el resultado de ese sistema que privilegió el voto indirecto y el poder del cuerpo legislativo en imponer resultados sorprendentemente, fue un importante compromiso ciudadano que, al final, preparó a la región para ampliar los derechos del ciudadano (al menos en el papel) durante la segunda mitad del siglo XIX.
\end{abstract}

Palabras clave: elecciones, siglo XIX, cultura política, votación

\section{«EL GOZE DE LOS DERECHOS DE CIUDADANO»: ELECTIONS AND CITIZENSHIP IN CENTRAL AMERICA, CA. 1770-1850}

\begin{abstract}
Between 1808 and 1850, the provinces and then independent Central American states organized hundreds of elections. This article examines the electoral theory set out in the region's constitutions and electoral regulations and explores the implementation as shown in election books, voter lists, newspapers, correspondence, and other documents that reveal voting and political practices at the municipal, state, and federal levels. The analysis shows that the surprising result of a system that privileged indirect voting and the power of the legislative body to impose results was a substantial citizen commitment to active political participation that ultimately prepared the region to expand citizen rights (at least on paper) in the second half of the nineteenth century.
\end{abstract}

Keywords: elections, nineteenth century, political culture, voting 
El 15 de diciembre de 1845, cuarenta votantes en la Nueva Guatemala de la Asunción (la Ciudad de Guatemala) protestaron ante el directorio (junta electoral) sobre el procedimiento de elecciones municipales realizado el día anterior. Solicitaron que la junta transmitiera al gobierno estatal las inquietudes procesales y sustantivas de no admitir sus votos. Sostuvieron que las urnas no se abrieron las ocho horas requeridas según lo indicado por un decreto reciente y que personas sin "el goze de los derechos de ciudadano" habían votado. Afirmaron que la circulación de "unas listas [de candidatos] impresas en azul", que reprodujeron "aberraciones y abusos" cometidos en 1837 y 1838, "no dejaba al pueblo la libertad necesaria para elegir a sus mandatarios" (Cabildo de Guatemala, 1845). Tomando este incidente al pie de la letra, podría parecer que el proceso democrático estaba bien establecido en Guatemala hacia 1845 , que los votantes eran muy activos, que conocían los cambios recientes a los códigos electorales y que utilizaban métodos conocidos de apelación; es decir, los ciudadanos no dudaron en ejercer su voz y voto.

Veinticinco atrás, en 1820, la Diputación Provincial (DP) de Guatemala discutió tres quejas sobre el fraude electoral en las elecciones parroquiales llevadas a cabo bajo el auspicio de la restaurada constitución española de 1812; dos de esas quejas denunciaron la circulación de listas de votación promovidas por poderosos residentes de la Antigua Guatemala y la Ciudad de Guatemala. Ambas reclamaciones fueron sustancialmente similares a las que se iban a presentar veinticinco años más tarde: implicaron el propósito de un sacerdote local de influir a los votantes para sufragar a favor de una lista de candidatos preseleccionados (Diputación Provincial, 9 de septiembre de 1820 en El Editor Constitucional, 1821, pp.534-535). La tercera denuncia provenía del "vecino Felipe Márquez" de San Martín quien se quejó de que "las elecciones de aquel pueblo se hicieron con exclusión del vecindario de ladinos, ${ }^{1}$ lo que afirmaron dos indios de los electores". Esta denuncia demuestra que el conocimiento y uso del nuevo sistema electoral había llegado más allá de la población de origen europea, al menos en los municipios principales.

Tomados en conjunto estos ejemplos de quejas sobre el funcionamiento del sistema electoral, se comprueba el compromiso ciudadano con la práctica electoral en la época de la independencia guatemalteca y, por extensión, de Centroamérica. También dan evidencia de una continuidad en las relaciones sociales y políticas trascurridas entre 1812 y mediados del siglo XIX, cuando los estados centroamericanos proclamaron y luego establecieron su soberanía política al subrayar "el goze de derechos de ciudadanía", tanto para las comunidades como para los individuos. Esta pluralidad de expresiones políticas no debe sorprender; incluso antes de la era de las revoluciones democráticas, los centroamericanos tenían una larga experiencia de involucramiento en los gobiernos local e imperial. En el siglo XIX, los habitantes de esta región continuaron con su compromiso de amplia participación individual y colectiva por medio de las reuniones populares, asistencia a elecciones y sorteos, y elevación de peticiones a las autoridades ejecutivas. 
Una evaluación de los orígenes de la democracia electoral en el período de independencia debería considerar no solo a quienes poseían legalmente el título de ciudadanos, sino a las formas en que los individuos y grupos expresaron "el goze de los derechos" que lo acompañaban y, en la práctica, cuáles eran las fuentes de estas expresiones para elegir o seleccionar a sus líderes políticos; en otras palabras, se debe analizar la nueva cultura política de participación y representación en conjunto con las prácticas desarrolladas durante el Antiguo Régimen, las cuales perduraron durante la etapa constitucionalista. De esa manera, se podrá reconocer la naturaleza experimental de los primeros esfuerzos jurídicos y constitucionales ${ }^{2}$. Porque, como Hilda Sabato (2006) ha subrayado, durante el siglo XIX "la adopción generalizada de formas republicanas de gobierno" en las Américas transformó la región en "un campo de experimentación política formidable" (p.263). Eso es justamente lo que se encuentra expresado también en la formulación de James E. Sanders (2011) al referirse a la "modernidad republicana americana" (p.105). Esta óptica de análisis permite entender los cambios vividos, tanto radicales e inclusivos como incrementales y exclusivos, como tentativas de buena fe propuestas por parte de actores educados y partidistas.

En las últimas décadas, los estudios centroamericanos enfocados en los procesos electorales decimonónicos han propuesto nuevos criterios para evaluar los orígenes de la democracia en la región ${ }^{3}$. Jorge García Laguardia realizó un importante estudio comparado del constitucionalismo en Cádiz y Centroamérica. ${ }^{4}$ Xiomara Avendaño $(1994,1995 a, 1995 b, 2014)$ estudió los procesos electorales en Guatemala, Nicaragua y la Federación a través de los códigos e impresos, mientras que Clotilde Obregón Quesada (2000) hizo lo propio con las elecciones presidenciales costarricenses (Avendaño, 1994, 1995a, 1995b, 2014). El libro de Avendaño (2007) sobre las elecciones indirectas en Nicaragua concluyó que este sistema produjo una ciudadanía débil, ya que junto a lo "individual" se mantuvieron antiguas estructuras corporativas dominadas, en su totalidad, por las redes montadas por las élites familiares. Discutir las tensiones entre la participación individual y comunitaria en la gobernanza fue así un paso importante para deshacerse de esa "camisa de fuerza" que exigía la pureza en los procesos políticos para considerarlos democráticos. Avendaño Rojas (2007) también proporcionó un punto de partida para incorporar el análisis de lo que Romana Falcón (2006) denominó el "arte de la petición” en la gobernanza democrática; de hecho, Falcón ya había sido citada en un análisis aplicado por Fabrice Lehoucq e Iván Molina (2002) en Costa Rica para comprender la eliminación gradual del fraude electoral a principios del siglo XX (Dym, 2001). Desde otro enfoque metodológico, Sonia Alda Mejías (2002, 2004a y 2004b) propuso una nueva comprensión de la política indígena y electoral en la Guatemala decimonónica, al enfatizar la importancia de las elecciones, incluso en tiempos de revolución, como medio para confirmar las transiciones políticas de poder: "el derecho de insurrección”. Esta visión de Alda Mejías contribuyó a evitar las suposiciones de que existe una comprensión única y correcta de la soberanía popular, así como de que la dependencia parcial de las prácticas democráticas deriva de su ineficiente implementación 
y la retención de jerarquías coloniales y la influencia eclesiástica (2014). A diferencia de Avendaño Rojas (2008), Alda Mejías destaca la importancia de los agentes populares, entre los que incluye a las comunidades indígenas. Trabajos adicionales de Avendaño Rojas y Sajid Herrera Mena sobre El Salvador y Ricardo Danilo Dardón Flores sobre Guatemala sugieren un creciente interés en el tema electoral.

A partir de esos estudios, este artículo explora la evolución de la forma particular de la elecciones de autoridades en Centroamérica en la confluencia entre las innovaciones de la era de las revoluciones, específicamente en el "experimento de Cádiz" y el constitucionalismo moderno, y sus bases en los derechos y prácticas políticas tradicionales de la comunidad. Es cierto que estas últimas fueron transformadas por el voto popular, la petición, el pronunciamiento y la insurrección, pero también tuvieron continuidades en las prácticas (y las formas) de selección de candidatos, la calificación de los votos, los nombramientos de mandatarios, y los diferentes estilos de 'consulta' que involucraron a diferentes individuos y organismos estatales en las decisiones electorales. En suma, se sugiere abordar dos temas para el caso de la institucionalización de la democracia en Centroamérica los cuales ha recibido menos atención. El primer tema es analizar el papel de la selección -y no tanto la elecciónde las autoridades nacionales y estatales como parte integral del sistema político, con raíces en tradiciones pactistas; específicamente, se consideran las raíces del nombramiento a funcionarios y miembros de gobierno por parte de las autoridades ejecutivas y legislativas, cuando el proceso electoral no produjo un candidato viable. El segundo tema por tratar es la propuesta de un marco analítico común para considerar las elecciones locales y federales o estatales.

\section{ELECCIONES AVANT LA LETTRE}

Aunque en muchos casos se estudian los procesos democráticos y electorales hispanoamericanos a partir de la monarquía constitucional establecida entre 1808 y 1814, es importante reconocer que el antiguo régimen español ofrecía formas de elección y representación limitadas pero importantes (Guerra, 1998; Quijada, 2005; Rodríguez, 2015), tal y como ocurría en otros gobiernos europeos (Manin, 1996). Estos procesos para los que ofrezco el neologismo "selectorales" y 'consultivos' eran fundamentales y fundacionales en preparar a los actores políticos independentistas. ${ }^{5}$

Los procesos 'selectorales' permitían a funcionarios e instituciones influir en las decisiones de los mandatarios después del voto ciudadano. A modo de ejemplo, los burócratas del Consejo de Indias prepararon ternas para que el Rey seleccionara funcionarios seculares y religiosos, al consultar y sintetizar los folletos de servicios y méritos preparados por los interesados para formar sus recomendaciones. En la América española, el Istmo centroamericano incluyó un sistema limitado de elección y selección de funcionarios locales cuya existencia databa del siglo XVI. Los concejales de las ciudades y villas de españoles elegían anualmente sus alcaldes, síndicos, 
y otros puestos municipales entre sus miembros. Hasta puestos vendibles, como los regimientos, podían convertirse en puestos bianualmente electos entre antiguos miembros del cabildo cuando carecían de compradores. Entre 1776 y la crisis política de 1808, en la capital de Guatemala, un boicot obligó al ayuntamiento a organizar elecciones bianuales para todos los regimientos, al permitir compartir cargos entre vecinos y, además, alternar entre peninsulares y americanos (Dym, 2006).

El proceso 'selectoral' pre-independentista no se limitó a la elite capitalina, sino que se hizo extensivo a diferentes clases y etnias. Las aldeas indígenas también seleccionaron sus alcaldes, con la aprobación del corregidor (Barrios, 1996). Asimismo, los gremios de artesanos, comerciantes y las universidades eligieron su liderazgo con prácticas similares. Además, en el siglo XVIII, una propagación de nuevas instituciones de afiliación profesional -el Consulado de Comerciantes, el Colegio de Abogados, y el Montepío de Añil- o de afinidad intelectual -la Sociedad Económica de Amigos del País y la Gazeta de Guatemala- contribuyeron a moticas una activa esfera pública y nuevas sociabilidades, además de extender la familiaridad con instituciones con reglamentos y oficiales, elecciones, y, a veces, concurrencia entre ellos para llenar puestos (Habermas, 1981; Woodward, 1965, p.549) ${ }^{6}$.

Por lo tanto, aunque limitado a ciertos puestos e instituciones, la práctica de seleccionar a los funcionarios locales transformó a las élites americanas y españolas en las ciudades, y también a las élites indígenas en los pueblos, cuyos consejos tenían una reconocida capacidad para negociar las prácticas de la justicia, la administración y los derechos de la comunidad con la metrópoli (Santos, 2000; Dym, 2006). A fines del siglo XVIII en Guatemala, en la medida en que se consolidó la disminución del interés en la compra de oficios municipales se extendió el llamado a elecciones que dieron voz y voto a un mayor número de vecinos. Aunque esta práctica se limitó a una experiencia concreta, conllevó a que cuando la crisis monárquica de 1808 abrió la puerta a nuevas instituciones y procesos políticos, no solo un puñado de la élite sino un porcentaje apreciable de vecinos ya hubieran participado en la selección de miembros del gobierno, de la administración municipal y de sus organizaciones profesionales.

Lo anterior se sumó al mecanismo de participación del Antiguo Régimen conocido como cabildo abierto, una práctica que consistió en reunir una comunidad amplia que incluía a vecinos y miembros del consejo municipal, de la Corona y de la Iglesia para participar en la toma de decisiones en momentos de crisis, por lo general mediante un acta, o documento, presentado a las autoridades superiores (Bayle, 1951, pp. 575-595). En otras palabras, las élites obtuvieron oportunidades políticas para participar como electores, aunque en circunstancias específicas, y para postularse para puestos imperiales y elegir autoridades locales. Además, un público amplio fue convocado para deliberar en circunstancias extraordinarias. Esta experiencia de localismos, tanto corporativos como individuales, demuestra que el reino de Guatemala no solamente experimentó una expansión en el gobierno bajo el régimen borbónico, sino experiencias de auto-gobierno, aunque limitadas a instituciones profesionales y locales. 


\section{ELECCIONES AL LLEGAR LA CRISIS IMPERIAL}

En las respuestas a la crisis política de 1808 , los métodos de representación política locales e imperiales del Antiguo Régimen se revitalizaron. Lejos de producirse una insurrección generalizada en América Central, la crisis monárquica abrió el camino para ampliar la representación municipal a nuevas clases sociales, hecho que condujo a una extensión de la participación individual y comunitaria, o corporativa, que hizo adaptar y mezclar las prácticas del Antiguo Régimen con innovaciones legislativas y constitucionales de la época.

El vacío de poder y la incertidumbre provocada por la abdicación de Fernando VII, así como el rechazo al intruso monarca francés José Bonaparte por parte del pueblo español, animaron a las élites en todo el imperio a aumentar su peso político mientras que los funcionarios reales dudaban de su propia autoridad y legitimidad. Aprovechándose de prácticas identificadas como "de tiempo inmemorial", las élites ofrecieron su lealtad a cambio de una mayor influencia en un momento en que la idea de representación territorial cobraba fuerza a nivel local e imperial. En Centroamérica, las élites convocaron a cabildos abiertos, a veces denominados "junti-ayuntamientos" por sus aspiraciones de querer gobernar, para justificar la sustitución de funcionarios reales de origen penínsular por naturales del lugar seleccionados por la comunidad, es decir, sujetos representativos. Algunos ayuntamientos en las provincias de Nicaragua, Honduras y El Salvador, además ampliaron la membresía y añadieron regimientos exclusivamente para representantes de los "barrios"; es decir, sectores ajenos a las élites que, aunque participaban en las deliberaciones, carecían de voz y voto permanente (Dym, 2008).

Cuando a nivel imperial, entre 1809 y 1810, las autoridades españolas reconocieron la necesidad de incluir a los territorios ultramarinos en los cuerpos gubernamentales imperiales, Centroamérica participó de esas oportunidades con entusiasmo, al elegir primero a un vocal a la Junta Suprema Central y luego a seis diputados a las Cortes de Cádiz en 1810 y 1812. El proceso 'selectoral' en ambos casos merece una reflexión. La convocatoria a elecciones de "un individuo cada cual que represente su respectivo distrito", para integrar la Junta Central en 1809, invitó a los ayuntamientos de españoles, sindicados como "capitales" (15 de 'distrito' en 1809, y 6 de 'provincia' en 1810) a "nombrar" una terna compuesta por individuos "de notoria probidad (sic), talento y instrucción" y sin "espíritu de partido", de forma que se decidiera por un sorteo "con la solemnidad de estilo" el elegido entre los tres y enviar "el testimonio del sugeto (sic) que haya salido en suerte' a la capital (en la Gazeta de Guatemala de 1810: 7 de marzo de 1810,pp. 277-282; 14 de junio de 1810,p. 39). Para seleccionar al vocal de la Junta Central, en 1809, una junta electoral compuesta por dos miembros del Real Acuerdo, del Cabildo eclesiástico y del Cabildo municipal, reunidos en la Ciudad de Guatemala, votaron con papeletas impresas para seleccionar de una terna de candidatos al ganador. En 1810, las capitales de provincia seleccionaron los seis diputados para las Cortes constitucionales bajo la misma metodología. Las actas impresas en la 
Gazeta indican que las elecciones se celebraron sin disturbios, y el reino aprendió la práctica del voto y acató los resultados como una comunidad (Ibidem y Archivo Histórico de Valencia; Decreto, Consejo de Regencia, 14 de febrero de 1810) ${ }^{7}$.

Las instrucciones electorales que iniciaron la transformación de Centroamérica en un espacio con derechos de representación en el imperio español fueron importantes. Primero, en la práctica del Antiguo Régimen, la "elección" combinó la voluntad humana (el nombramiento) con la voluntad divina y azarosa (la suerte). Igualmente, podría considerarse como una combinación de ideas de representación y autoridad individual y comunitaria tanto tradicionales como ilustradas (Dardón, 2008). El sorteo a través del cual un niño extraía una papeleta con el nombre del beneficiario, se consideraba como "un voto secreto en forma ordinaria" según el Libro de Cabildo (1809). En segundo lugar, los decretos que establecían el procedimiento electoral se referían a las "elecciones", pero calificaron la votación de los ayuntamientos para candidatos como "nombramiento" y la lotería como "sorteo", lo que demuestra que en esta época se consideraba la selección como una etapa elemental para las elecciones (Real Orden, Junta Central, 22 de enero de1809; Decreto, Consejo de Regencia, 14 de febrero de 1810). Tercero, las instrucciones de 1810 para los diputados a Cortes también especificaban que las elecciones debían anunciarse con anticipación y hacerse a "puertas abiertas", e invitar al pueblo a observar más no a participar (Decreto, Consejo de Regencia, 14 de febrero de 1810, Art. 16). Este proceso demuestra la plasmación de la ciudadanía colectiva que Avendaño identificó, al pasar de las prácticas tradicionales a las del siglo XIX a través de individuos que votaban y comunidades que se expresaban a través del voto colectivo.

Una inédita práctica electoral comunicada por la Gazeta de Guatemala a los administradores y suscriptores, entre Chiapas y Costa Rica, anunció el fomento de nuevas identidades políticas. A nivel regional, se dio peso al reino como territorio político y ya no solamente administrativo (Dym, 2009, p.99-118). A nivel local, el sistema imperial elevó a los quince ayuntamientos centroamericanos al rango de "capitales de distrito" y a una posición de representantes reconocidos de su comunidad, en cierto sentido, equivalente en estatus a los reinos y distritos peninsulares (Dym, 2006). Tratar a las municipalidades como entidades representativas dentro del sistema imperial las revitalizó, sobre todo, a través de su participación en la celebración de las elecciones y en la preparación de instrucciones sobre asuntos "generales o particulares" para la Junta Central y, más tarde, para los delegados a Cortes (España Junta Central, Real Orden, 22 de enero de 1809; Consejo de Regencia, Decreto, 14 de febrero de 1810). Las élites respondieron con una inusitada muestra de interés por acceder a los cargos municipales. Consejos inactivos se reanimaron e, irónicamente, los regimientos vacantes por treinta años en Ciudad de Guatemala se vendieron para poder participar en la instancia regional (Obregón, 2000, p.29; Dym, 2006, pp.78-79).

El largo proceso electoral para nombrar al representante centroamericano a la Junta Central se extendió por cerca de un año y exigió la cooperación de quince distritos para seleccionar a seis diputados de las Cortes. Eso proporcionó un cierto 
sentido de unidad al sistema político centroamericano, a pesar de que las elecciones tuvieron lugar "en fechas muy distintas, según las distancias, y ocurrencias (sic) que en algunas partes se ofrecieron" (Gazeta de Guatemala, 7 de marzo 1810, p.273). Pero, de manera previsible, las instrucciones preparadas por los ayuntamientos para los diputados, lejos de aspirar a una integración mayor, tuvieron un carácter excesivamente localista al recomendar, en gran medida, la construcción de colegios o universidades, el establecimiento de obispados o el aumento del comercio a un puerto local. Por eso, aunque los primeros diputados originarios de la Capitanía General de Guatemala, especialmente Antonio Larrazábal (Guatemala), Florencio Castillo (Costa Rica) y Antonio López de la Plata (Nicaragua), se unieron con otros americanos en las Cortes para hacer causa común en temas como la libertad de comercio y el sufragio para los americanos de origen africano, no les interesó que la Capitanía General adquiriese una identidad regional (Dym, 2008, pp.105-137).

Los académicos coinciden en que el "experimento de Cádiz" introdujo nuevas instituciones representativas en una sociedad que, por lo general, pareció acogerlas. A su vez, confirman la importancia que adquirió una política comunitaria junto con la introducción de la ciudadanía y la representación individual (Rodríguez, 1978). Cuando Centroamérica implementó la constitución de 1812 -tanto en 1813-1814 como en 1820-1821- a través del sistema de elecciones indirectas, los residentes aprendieron a votar localmente por los concejales municipales, por los electores que elegirían, o "nombrarían", a los diputados imperiales a Cortes y por los electores regionales a las dos nuevas diputaciones provinciales radicadas en Guatemala y Nicaragua.

El nuevo proceso de votación para los diputados provinciales fue complicado, pero aparentemente exitoso. Los ciudadanos votaron en voz alta, individual y públicamente, por sus electores en elecciones parroquiales el primer domingo de diciembre. Los electores vijaron a las capitales y votaron por escrito por los titulares de cargo el primer domingo de enero en las elecciones de distrito. Era prohibido votar por sí mismo bajo pena de perder el derecho a votar. También podían reclamar el voto de otro; la junta electoral evaluaba la denuncia oral en el acto. En cada etapa, los votantes eligieron al secretario y a los escrutadores de una junta electoral, presidida por la autoridad local, que escuchó y contó cada voto y luego certificó los resultados. El ganador se decidía por mayoría simple; así que ni la suerte ni Dios imponían ahora un vencedor. Además, cada pueblo aceptó que los electores de distrito participaran en un proceso que reflejaría la voluntad de varias comunidades. El método electoral creado por Cádiz -indirecto, de distrito y con base de votos orales- formaban la base del sistema adoptado después de la independencia en 1824 y hasta fines de la década de 1830 (España, Constitución de 1812, Arts. 37, 61).

Otro paso hacia una democracia de ciudadanos establecida en la Constitución de Cádiz era acabar con la distinción política entre españoles y naturales o indígenas. En Centroamérica, además, se interpretó la Constitución para incluir a los hombres libres de origen africano en el cuerpo político como ciudadanos "españoles". El número de representantes se basó en la población y no en la etnicidad. En la práctica, 
este sistema electoral redujo las distinciones políticas ( si no es que podrían catalogarse de diferencias socio-económicas) de la jerarquía racial de la época colonial, ya muy compleja después de trescientos años de mestizaje y convivencia, y allanó el camino para incorporar a todos los hombres mayores de edad como ciudadanos en las elecciones posteriores a la independencia; las mujeres no tenían voz directa pero casarse otorgó derechos políticos a esposos nacionales y extranjeros (Dym, 2006; Dym 2009, p.46-48).

Aunque ningún estudio exhaustivo rastrea las elecciones de cada pueblo y aldea, los archivos muestran que el gobierno representativo se arraiga a través de elecciones celebradas en todo el istmo en 1813-1814 y, nuevamente, en 1820-1821. En ambos contextos, Centroamérica instaló las dos diputaciones provinciales autorizadas por la constitución y formó cientos de ayuntamientos constitucionales (Dym, 2006). En las ciudades regionales, nuevos grupos sociales entraron en los ayuntamientos. Guatemala, Tegucigalpa y Sonsonate, entre otros, eligieron a individuos de las clases trabajadoras e incluso de una herencia racial mixta (Dym, 2005, pp.257-283; Dym, 2006, p.128-138). Además, las fuentes municipales revelan numerosos votantes en pueblos indígenas. Un listado de votantes de 1813 en San Miguel Petapa (Guatemala), estudiados por Ricardo Dardón Flores (2008), registra 375 ciudadanos con derecho al voto en una población de alrededor de mil almas, según un censo de la época (párr. 48). En algunos lugares, los residentes indígenas tuvieron que ser convencidos para adoptar el nuevo sistema; en otros, ellos aprovecharon las elecciones para remplazar a los ladinos en los ayuntamientos constitucionales. No fue inusual cuando el pueblo de Cobán, en una zona maya en las tierras altas de Guatemala, eligió 10 "indios" para los 12 cargos municipales, en 1820 (Del Valle, 1969, p.48). Al aprovecharse del vocabulario político más conveniente, los pueblos indígenas no dudaron en recordar a las nuevas autoridades de los privilegios e identidades antiguos. Un ejemplo fascinante es una queja de 1822, en la cual el elector de distrito, el "indio natural” Juaquín Cham de Chimaltenango (Guatemala), protestó que el 'corregidor' (jefe político) había trasladado el local de votación fuera de su pueblo. "No parece justo", escribió, "que este pueblo, ayuntamiento y vecindario pierdan las prerrogativas que hasta ahora les correspondían". El elector, que se presentó como tal ante el cuerpo constitucional, aludió a los derechos de su comunidad, no a sus prerrogativas individuales, y es muy significativo que ni él ni los que recibieron su consulta vieron como contradictorias esas identidades (Cham, 1822, AGCA).

Aunque la estructura electoral indirecta de la legislación gaditana fue más inclusiva que las prácticas gubernamentales del Antiguo Régimen, aquella tuvo serias limitaciones para crear un cuerpo político totalmente igualitario. En la mayoría de los distritos, los electores, los diputados a Cortes y los diputados provinciales eran de origen europeo. Dardón encontró que seis de los once electores de parroquia que se reunieron en Antigua, Guatemala, eran alcaldes, y solo uno era de origen maya (Dardón, 2008, p.44-48) ${ }^{8}$. El sistema requería que los electores dispusieran de tiempo y de caudales propios para asistir a las capitales de distrito, aunque se suponía que los electores recibían un viático diario (Obregón, 2000, p.46.; Dym, 2006, pp.128131). En consecuencia, el sistema electoral escalonado de la reglamentación gaditana 
mantuvo una autoridad sustancial en la toma de decisiones de manos de personas con capital económico y social, generalmente miembros de la iglesia o miembros de familias ricas o pudientes, y personas de herencia europea (Avendaño, 1995a; Dym, 2006).

¿Qué libertad tenían los individuos para votar en estas tempranas elecciones? El sistema no permitía candidatos y las actas electorales no indican cómo eran seleccionados por los individuos. El expresarse a partir de los votos orales durante las juntas de parroquia, aunque quizás supliera eficazmente la carencia de alfabetización, podría haber dificultado la diversidad de opiniones. Sin embargo, las actas electorales no anotan unanimidad de votos. La mayoría de las elecciones registradas muestran un apoyo simbólico por varias personas, lo que sugiere cierto margen para el debate y la elección, como se ve en el libro de elecciones de Tegucigalpa (Honduras), donde excepcionalmente, para este período, se cuenta con registros completos de elecciones municipales. La elección de diciembre de 1812, del primer ayuntamiento constitucional, parece típica: 17 electores se reunieron para sufragar a los miembros de la corporación en 1813; los que ganaron recibieron entre 8 y 13 votos, y los nominados tenían un mínimo de 3 y un máximo de 13; cuando un alcalde electo declinaba el cargo, la junta elegía inmediatamente un reemplazo entre los que habían obtenido más votos (Ayuntamiento de Tegucigalpa, 1812, ANH).

Por lo demás, el número de quejas presentadas ante las autoridades centrales sobre derecho al voto, presión para votar por una lista de candidatos y derecho a participar en los consejos electorales muestra que hubo intentos de influenciar y, a veces, de coaccionar a los electores. ¿Fueron estas denuncias signos de fraude o de influencia indebida? Hasta cierto punto, los informes sobre conflictos electorales podrían indicar cómo la expansión de derechos y de individuos que servían en los nuevos ayuntamientos constitucionales, fue percibida por algunos como una amenaza, y por tanto, sugieren más un problema de apertura o un aprendizaje que una limitación. A modo de ejemplo, considerése la descripción de las elecciones de diciembre de 1813 redactada por el Capitán General José de Bustamante, quien de ese modo intentó frenar o bloquear las nuevas instituciones: Bustamante lamentó que la embriaguez, el juego, la incontinencia, la ilegitimidad, la pobreza voluntaria y las malas costumbres sirvieran como obstáculo a las presentes elecciones; denunció los problemas generados por la elección de personas incapaces de llevar a cabo funciones municipales, analfabetos y sin poder promover utilidad para el estado. Dio noticia de fraudes y erupción de rivalidades peligrosas, y las atribuyó a "que individuos deseosos de exaltarse a sí mismos habían buscado cargos municipales por medios que los hombres de fe u honor desconocen” (Bustamante, 1814, AGI Guatemala 629). Sus quejas, más que problemas electorales, parecían testimoniar tanto un asunto de apertura e inclusión, por un lado, como, por otro lado, preocupaciones elitistas sobre la alfabetización y el nacimiento legítimo que la constitución no solicitaba, así como la pérdida del "honor" como criterio para una correcta actividad política.

De hecho, algunas denuncias confirman una incipiente participación popular en la política municipal. Cuando en 1820 el maestro artesano Ambrosio Sánchez, en Ciudad de Guatemala, alegó que se le privó injustamente de su derecho al voto, el 
Jefe Político Superior consideró los artículos de la Constitución, así como las leyes extraídas del Diario de Cortes, para dictaminar que "en estas materias más bien debe ampliarse que restringirse su significado conforme a los principios generales en derecho" (Caso de Ambrosio Sánchez, 1820, AGCA). La ampliación de la participación popular deja ver un crecimiento de la esfera pública.

El interés público en las elecciones fue alentado por aquellos que tuvieron a su cargo la prensa periódica guatemalteca. Noticias e informaciones sobre las elecciones parroquiales y provinciales, así como los nombres de los representantes electos a Cortes y diputaciones provinciales, aparecieron en la Gazeta de Guatemala, órgano oficial del reino, hasta que Fernando VII fue restaurado en el trono en 1814. A partir de 1820, al restablecerse la Constitución, Pedro Molina a través de El Editor Constitucional y José Cecilio del Valle por medio de El Amigo de la Patria divulgaron el acalorado debate suscitado entre los electores durante las elecciones municipales de la ciudad de Guatemala en 1821. Cuando el baco del Valle fue elegido alcalde primero de la Ciudad de Guatemala, los periódicos vigorosamente debatieron la legitimidad de este sufragio (Marure, 1960, p.122). Esta controversia se prolongó hasta después de la independencia, cuando las etiquetas cambiaron de cacos (ladrones) a fiebres (calentones o cabrones) y de liberales y de bacos (borrachos) a serviles y conservadores (Marure, 1960, pp.58-60; Woodward,1965, pp.561562). La prensa aplicó estos términos para dar color a las políticas y acciones de los grupos contendientes (Woodward, 1965, p.565)

En resumen, el período de crisis de la monarquía constitucional española expandió la política electoral, así como la centralidad municipal dentro del sistema político, e introdujo la idea de la participación política basada en intereses compartidos en lugar de, o además de, la pertenencia étnica. Si bien la Constitución no introdujo el proceso electoral en Centroamérica, sí expandió los derechos de ciudadanía más allá de unos pocos miembros selectos de los ayuntamientos o gremios.

Además, a pesar de sus defectos, el sistema echó raíces durante este periodo y eso permitió que se extendiera el sufragio más allá de la limitada participación política que había sido la tónica en los siglos anteriores; especialmente importante fue la inclusión de las personas de ascendencia africana no incluidas en los documentos imperiales. Mostró de esa manera una considerable voluntad para adaptar la política oficial a las demandas locales. Así, la aplicación local de la convocatoria electoral imperial auspició la inclusividad étnica pero, a la vez, dejó entrever las futuras dificultades en la implementación de una ley al pie de la letra, lo que luego socavaría las instituciones constitucionales. En cuanto a los precedentes para sistemas electorales posteriores, se debe enfatizar que el engorroso proceso electoral indirecto para elegir diputados de Cortes y de diputaciones provinciales tuvo un resultado poco considerado pero duradero: los ciudadanos que votaban en sus municipios de origen, siguiendo el sistema electoral indirecto establecido en 1812, perdieron el derecho de votar directamente por las figuras regionales y nacionales que tenían en 1809. El sistema fortaleció la centralidad y legitimidad política de las autoridades 
municipales y legislativas que los electores seleccionaron, mientras que el rey y sus consejos nombraban los puestos ejecutivos y judiciales. También extendió el proceso de consulta y petición, por parte de individuos y comunidades, a las diputaciones provinciales para resolver dudas o problemas administrativos.

\section{ELIGIENDO LA INDEPENDENCIA}

En el proceso de independencia de 1821-1822, la articulación de la preferencia u opinión política adoptó dos formas distintas: los votos expresados por los ayuntamientos constitucionales elegidos después de los cabildos abiertos y los llamamientos a las personas para que deliberaran y tomaran decisiones en una asamblea regional. Al llegar las noticias de la independencia novohispana y del plan mexicano de las Tres Garantías a diferentes distritos, los ayuntamientos centroamericanos convocaron a cabildos abiertos para deliberar sobre el asunto, y eso comenzó en Chiapas, en agosto de 1821, y continuó en septiembre en la capital, Ciudad de Guatemala y, finalmente, en octubre en Costa Rica. En Ciudad de Guatemala, el 15 de septiembre de 1821 la junta integrada por las autoridades reales y las élites locales convocó una reunión de "diputados" de las principales instituciones seculares y religiosas para emitir un acuerdo, o acto, redactado por la Diputación Provincial y el ayuntamiento. El documento, considerado posteriormente como el acta de emancipación, expresó una preferencia gradual por la independencia: se mantuvo a las autoridades existentes, se convirtió a la diputación provincial en Consejo de Gobierno interino y se convocó a cada distrito del reino a que enviaran representantes para votar la independencia en una asamblea regional y para seleccionar un nuevo gobierno. Así, un cuerpo deliberativo o soberano tradicional, el cabildo abierto, convocó a una institución republicana, una asamblea constituyente con delegados de los distritos políticos centroamericanos y dio un paso hacia el reemplazo de las múltiples soberanías en las que las ciudades o distritos poseían fracciones del conjunto, por una soberanía y representación unitaria gobernada únicamente por una asamblea.

Sin embargo, la iniciativa guatemalteca no produjo los resultados deseados. En lugar de coordinar esfuerzos en elegir diputados para una asamblea constituyente, muchos municipios y la Diputación Provincial nicaragüense emitieron sus propias actas para unirse por separado a México o a Guatemala. Las ciudades de Costa Rica, divididas entre invitaciones rivales de Guatemala y Nicaragua, tuvieron la previsión de firmar un pacto "de concordia" para restablecer su acuerdo social y comprometerse con una soberanía e identidad provinciales. En este caso, las corporaciones tradicionales, los ayuntamientos, eligieron delegados para firmar el acuerdo, y así se combió formas antiguas y nuevas de conocimiento político. A través de las actas de las ciudades, de diputaciones provinciales y de cabildos abiertos, se nota que hubo extensa participación popular en la toma de decisiones. A pesar de ello, no actuaron 
como si una soberanía única podría formarse para dictar acuerdos en nombre de todos los distritos y habitantes de América Central.

Para mantener una apariencia de unidad, en noviembre de 1821, la junta de la Ciudad de Guatemala abandonó la esperanza de reunir una asamblea constituyente y, en su lugar, convocó a un referéndum municipal para decidir el futuro de la Audiencia. La junta invitó no solo a las capitales, sino a todas las ciudades y pueblos con ayuntamiento constitucional a participar después de consultar la voluntad de los residentes. La junta luego de contar los votos recibidos, 168 de 244, y también interpretar las decisiones de las provincias que ya habían optado por unirse a México como parte de un proceso unitario, acordó el 5 de enero de 1822, en el Acta de la Unión, dar un voto mayoritario por la anexión a México (Valle, 1924-1949, pp.24-27; Luján, 1982, pp.171-75; Dym, 2006).

Habida cuenta de que tradicionalmente se asocia la participación "popular" con personas que expresan sus opciones a través del sufragio, llama la atención que esta dependencia en las municipalidades como órganos de adopción de decisiones resultara problemática, aunque los cabildos consultados fueran elegidos popularmente y no solo fueran las capitales controladas por las élites, sino también ciudades y aldeas provinciales.$^{10}$ Hacia 1834 , el político e historiador oficial Alejandro Marure (1960) desestimó el referéndum, al recordar a los lectores que el Capitán General en funciones había dicho a las regiones secesionistas que los ayuntamientos no tenían autoridad para decidir y que la "voluntad [general de los pueblos] solo podía expresarse por un congreso formado de diputados elegidos por los mismos pueblos “(p.85). Sin embargo, otra forma de evaluar el complejo proceso de independencia de Centroamérica es considerar que la votación municipal abrió el debate a más de doscientas comunidades, no solo para seleccionar un notable local para negociar los próximos pasos sino, también, para incorporar directamente a los electores y residentes en el asunto de decidir la forma de independencia, y se basó tanto en la tradición como en las nuevas instituciones representativas creadas por la Constitución de 1812. Se puede decir que los pueblos centroamericanos eligieron su emanicpación de España al optar por su dependencia del ex virreinato de Nueva España.

\section{ELECCIONES EN UN SISTEMA FEDERAL}

Después de una efímera anexión a México en 1823, unos 40 diputados centroamericanos volvían a casa del congreso mexicano trayendo consigo una experiencia parlamentaria mayor y varios de ellos fueron inmediatamente elegidos a la Asamblea Nacional Constituyente. O sea, el congreso esperado desde el 15 de septiembre de 1821, que se reunió en Ciudad de Guatemala a mediados de 1823, declaró la independencia absoluta de España y México y deliberó la formación de una federación con cinco estados: Guatemala, Honduras, El Salvador, Nicaragua y Costa Rica. $\mathrm{Al}$ conseguir la independencia absoluta, el desafío centroamericano en erigir un 
gobierno asentado en la soberanía popular no fue tanto escoger entre los sistemas de gobierno monárquico y republicano; era más bien formar un sistema federal factible, con instituciones complementarias creadas por el congreso federal por un lado, y cinco legislaturas estatales, por el otro.

El historiador Mario Rodríguez (1978) ha indicado con acierto que los primeros años federales centroamericanos fueron una extensión de la experiencia de Cádiz. En términos del procedimiento electoral, este período queda comprendido entre 1826 y 1839 , cuando la federación se disolvió y las nuevas constituciones introdujeron cambios sustanciales. Hasta 1839, el gobierno federal y los gobiernos estatales adaptaron un modelo constitucional que parecía haber funcionado relativamente bien antes y después de la independencia, y las elecciones se convirtieron en una característica habitual de la vida política, aunque no fueron el único medio por el que el poder político cambió de manos. Sin embargo, en este período se estableció, por primera vez, una característica importante del gobierno representativo centroamericano: la selección de los titulares de cargos nacionales por las asambleas legislativas cuando las elecciones populares no producían candidatos con clara mayoría.

La estructura de la Centroamérica republicana tenía elementos significativos que pueden considerarse "democráticos". Los legisladores de la Asamblea Nacional Constituyente no eran demasiado idealistas. La constitución federal de Centroamérica de 1824 estableció un gobierno "popular, representativo, federal" que reclamaba la soberanía nacional (Arts. 1, 8). Las cinco constituciones estatales, promulgadas entre 1824 y 1826, adoptaron una misma estructura política básica con la separación de las ramas ejecutivas, legislativas y judiciales, aceptaron la soberanía limitada a asuntos internos y establecieron requisitos complementarios para los cargos y servicios públicos. Esta estructura común se basó en gran medida en la legislación de Cádiz para el proceso electoral, las elecciones legislativas y la gobernanza municipal. La elección de las autoridades ejecutivas y judiciales se inspiró en los modelos estadounidense, francés y sudamericano, ya que el sistema gaditano no contempló la elección de los poderes ejecutivo y judicial ${ }^{11}$. Además, en la definición de la ciudadanía, no sólo se abandonaron las "repúblicas" separadas de españoles e indígenas, sino que, a partir de la consideración del nacimiento y raza (ius solis y sanguinis), se extendió la calidad de ciudadano a los hombres mayores de edad a partir de los criterios temporales de residencia (ius domicilis) y lealtad y, a veces, del matrimonio con una mujer lugareña mientras, como otras repúblicas americanas, aprendieron a legislar distinciones entre habitantes, nacionales y ciudadanos (Dym 2009 (2006), esp. p.14-27) ${ }^{12}$. Tampoco se añadieron criterios socioeconómicos de propiedad ni de alfabetización que podrían haber privado de derechos políticos a los hombres pobres o marginados. La decisión centroamericana de incluir formalmente como ciudadanos a los hombres de origen africano fue la secuela del anuncio de la abolición de la esclavitud por parte de la Asamblea Nacional Constituyente (España, Constitución de 1812, Art. 25.6. ANC, 1832, AGCA). La participación e influencia política de las 
mujeres de todas clases, destacada en levantamientos y actividades públicas como cabildos abiertos y juramentos en todas las Américas, no llegó a su inclusión política con derechos formales como el voto. ${ }^{13}$

En la política electoral, las primeras Constituciones federales y estatales centroamericanas reprodujeron la estructura básica de la constitución española de 1812, y establecieron elecciones populares que tenían que ser públicas para ser válidas (Centroamérica, Constitución, 1824, Art. 3; Costa Rica, Constitución, 1825, Art.35). Adoptaron el intrincado proceso de elecciones populares indirectas por las cuales los ciudadanos seleccionaban a sus consejeros municipales y "electores de partido", estos a su vez seleccionaban a los "electores de departamento", y, por último, elegían a los miembros de las asambleas legislativas estatales y federales. Las juntas departamentales también debían emitir sus votos para los cargos ejecutivos y judiciales, así como para el cuarto "poder conservador", semejante a un senado, para su posterior calificación por parte de la asamblea respectiva (Centroamérica, Constitución Federal, 1824, Tit. X; Guatemala, Constitución, 1825, Tít. III; Nicaragua, 1826, Tít. V; Costa Rica, 1825, Cap. 5) ${ }^{14}$. La diferencia era que, si ningún candidato triunfaba con una mayoría simple, las asambleas federales o estatales se encargaban de seleccionarlo de entre los candidatos. Para anticiparse a problemas de legitimidad, un perspicaz diputado propuso establecer que una asamblea legislativa solo pudiese elegir al vencedor entre los candidatos con mayor número de votos populares, pero la proposición fue rechazada (ANC, 1824, AGCA, f. 4). Sin que los legisladores se dieran cuenta, el proceso 'selectoral' introducido con la constitución gaditana amplió su presencia al periodo nacional.

Aunque hubo pocos cambios en el marco del proceso electoral de la monarquía constitucional, el sufragio funcionó de modo distinto dentro de un gobierno representativo, algo primero visible por el número de puestos elegibles. Antes de la independencia, solo elegían a un puñado de funcionarios legislativos y administrativos, esto es, a los diputados a Cortes y a la Diputación Provincial. En 1824, en cambio, los legisladores centroamericanos adaptaron en sus constituciones el complejo modelo para todas las ramas y niveles del gobierno, con excepción importante de los jefes departamentales, nombrados por el poder ejecutivo, en base de una lista propuesta por el Consejo Representativo en el papel del Consejo de Indios (Centroamérica, 1825, Art. 102; El Salvador, 1824, Art. 35.6; Guatemala, 1825, Art. 127; Honduras, 1825, Art 38.5; Nicaragua, 1826, Art. 99.5). El aumento cuantitativo y cualitativo de las elecciones y del número de cargos previstos por el sistema electoral ha recibido poca atención en la historiografía centroamericana. Quizás doscientos años de republicanismo en las Américas hacen que tales elecciones parezcan naturales. En aquel momento, sin embargo, al menos un diputado preguntó si sería incómodo llevar a cabo elecciones y encontrar candidatos para los 286 puestos públicos que calculaba eran necesarios para que los seis gobiernos funcionasen. La implementación no tardó en dar una respuesta realista: algo así sería difícil de alcanzar (Marure, 1960 [1837], pp.202-203) ${ }^{15}$. 
La Constitución de 1812 podría haber acostumbrado a los centroamericanos a elegir a sus funcionarios y representantes municipales para una asamblea regional, pero realmente nada los preparó para elegir a casi 300 funcionarios estatales y federales en funciones ejecutivas o judiciales. Fue una verdadera innovación que las constituciones de la década de 1820 se comprometieran enteramente a elegir por voto popular (aunque indirecto) a la mayoría de las autoridades ejecutivas, judiciales y legislativas más importantes. Antes de la independencia, la única elección a nivel regional para un representante para toda Centroamérica fue en la elección de 1809 para el delegado de la Suprema Junta Central, quien nunca viajó ni se integró a esa junta.

En las primeras elecciones presidenciales, algunos centroamericanos tenían suficiente perfil regional para atraer votos populares sustanciales, como los dos concursantes que dividieron los votos en la primera presidencia federal en 1825: José Cecilio del Valle, de Choluteca, Honduras y Ciudad de Guatemala, autor del acta de independencia, funcionario real y periodista; y Manuel José Arce, de San Salvador, el líder en 1821 de la oposición a la unión de El Salvador a México (Parker, 1952, pp.533-534). Los excelentes estudios sobre las elecciones decimonónicas en Nicaragua hechos por Xiomara Avendaño (2007) han sugerido que, en general, se respetaron e implementaron los complejos procedimientos de votación a tres niveles (Obregón, 2000). Del mismo modo, documentos electorales y legislativos que cubren el proceso electoral entre 1820 y 1840 en Sonsonate (El Salvador), la Ciudad de Guatemala y Antigua (Guatemala), y Tegucigalpa y Danli (Honduras) indican que los ciudadanos y las juntas se reunieron regularmente, leyeron en alta voz la legislación vigente, abordaron los desafíos con las calificaciones de votantes y, por último, votaron (Avendaño, 2007) ${ }^{16}$. El número de elegibles varió según la elección. Si bien varios miles de electores participaron en la selección de los electores de partido, en Guatemala y Costa Rica, respectivamente, hubo 162 y 119 electores de distrito en 1825 (ver Figura 1); por su parte, Nicaragua tuvo entre 90 y 180 electores de distrito en el período federal (Avendaño, 2007, p.166).

La tabla muestra la complejidad y funcionamiento de un sistema electoral con muchas etapas y varios niveles. Costa Rica fue el único estado que adoptó requisitos distintos para votar en las elecciones estatales y federales (Figura 2). Presumiblemente, los costarricenses quisieron garantizar una mayor participación de los votantes en el estado con la población más pequeña en la que la representación legislativa por cada $30.000 \mathrm{o}$ incluso 15.000 habitantes (las cifras seleccionadas por los otros Estados) produciría una legislatura estatal con cuatro miembros. 


\section{T A B L A}

á que deben arreglarse los partidos del Estado do Costa-ricapara la eleccion de sus Diputados.

Bssta sễal A. manifiesta donde deben reunise los clectores parroguiales á nombrar los de partido, I esta B. donde los de partido á

elegiri los Diputados Y Suplentes, igualmente que

sufragar para los otros Supremos

Poderes del Bstado.

\section{ELECTORES.}

\begin{tabular}{|c|c|c|c|c|}
\hline PARTIDOS. & DE PARROQUIA. & DE PARTIDO. & Diputados. & Suplentes. \\
\hline $\begin{array}{l}\text { De San Jose } \\
\text { Almas } 16,288\end{array}$ & $\begin{array}{lrr}\text { San Jose. } & \text { A. B. } & 31 \\
\text { Curridabat } & & 1 \\
\text { Aserri } & & 1\end{array}$ & 11 & 3 & 1 \\
\hline $\begin{array}{l}\text { De Cartago } \\
\text { Almas } 12,330\end{array}$ & $\begin{array}{lrr}\text { Cartago. } & \text { A. B. } & 22 \\
\text { Cot } & 1 \\
\text { Quircot } & & 1 \\
\text { Tobosi } & & 1 \\
\text { Tres-Rios } & & 1\end{array}$ & 8 & 2 & 1 \\
\hline $\begin{array}{l}\text { De Feredia } \\
\text { Almas } 12,260\end{array}$ & $\underset{\text { Barba }}{\text { Heredia. }} \quad$ A. B. $\quad \frac{22}{3}$ & 8 & 2 & 1 \\
\hline $\begin{array}{l}\text { De Alafuela } \\
\text { Atmas 8,027 }\end{array}$ & Alajuela A. B. 16 & 5 & & \\
\hline $\begin{array}{l}\text { De Bagaces } \\
\text { Almas 1,444. }\end{array}$ & $\begin{array}{lll}\text { Bagaces } & \text { A. } & 1 \\
\text { Cañes } & & 1 \\
\text { Esparza } & & 1\end{array}$ & 1 & 2 & $\mathbf{1}$ \\
\hline $\begin{array}{l}\text { De Escasti } \\
\text { Almas 3,273. }\end{array}$ & $\begin{array}{lll}\text { Escasú } & \text { A. B. } & 5 \\
\text { Pacaca } & & 2\end{array}$ & 3 & 1 & 0 \\
\hline $\begin{array}{l}\text { De Cjarras } \\
\text { Almas 2,505. }\end{array}$ & $\begin{array}{lll}\text { Ujaarras } & \text { A. B. } & 3 \\
\text { Orosi. } & 2 \\
\text { Tucurrique. } & & 1\end{array}$ & 2 & \multirow{2}{*}{1} & \multirow{2}{*}{0} \\
\hline $\begin{array}{l}\text { De Terrabs } \\
\text { Almas } 1,019 .\end{array}$ & $\begin{array}{lll}\text { Terrabe. } & \text { A. } & 2 \\
\text { Boruca. } & & \end{array}$ & 1 & & \\
\hline
\end{tabular}

San Jose Enero veinte y seis de mil ochocientos veinte y cinco.-

El Dlputado Secretario

Manuel Fernandez.
El Diputado Secretaikio. Felix Romero. 


\section{Tabla á que deben arreglarse las elecciones de individuos para los}

Supromos Podoros do la Republica.

\begin{tabular}{|c|c|c|c|c|c|c|}
\hline Departamentos. & DISTRITOS. & PUEBLOS. & KLECTORKS PIIMARIOS. & De disiritu. & | licpresenturtex. & Suplenter. \\
\hline \multirow{4}{*}{ 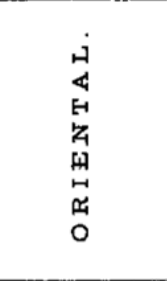 } & Do San Jose. & $\begin{array}{l}\text { San Jose } \\
\text { Curridabat. } \\
\text { Aserfi. }\end{array}$ & 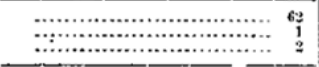 & 6 & & \\
\hline & De Cartago. & 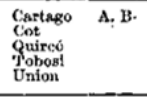 & 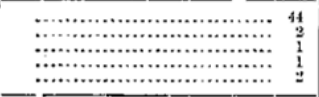 & 5 & \multirow[t]{3}{*}{1} & \multirow[t]{3}{*}{1} \\
\hline & De Ujarras. & $\begin{array}{l}\text { Ujurras } \\
\text { Thentrifgue } \\
\text { Orosi }\end{array}$ & ר... & $1^{\circ}$ & & \\
\hline & Do Terraba. & $\begin{array}{l}\text { Terraba } \\
\text { Boruca }\end{array}$ & 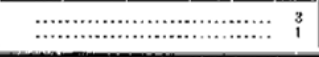 & 1 & & \\
\hline Depariamcntos. & DISTRITOS. & PUEBLOS. & ELECTORES IRIMARIOS. & De distrito. & Jicpresententers. & Suplentes. \\
\hline \multirow{4}{*}{ 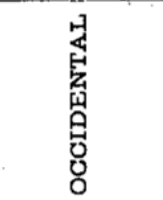 } & De Alajuetix. & Alajucls A. B. & …....................... & 4 & \multirow{4}{*}{1} & \multirow{4}{*}{1} \\
\hline & De Escasú. & $\begin{array}{ll}\text { Egeasí } \\
\text { Pacaca }\end{array}$ & 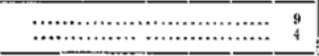 & 2 & & \\
\hline & De Cañac. & $\begin{array}{l}\text { Cañias } \\
\text { Kangaces } \\
\text { Esporzza }\end{array}$ & $\begin{array}{ll} & \\
7\end{array}$ & 1 & & \\
\hline & De Heredia. & $\underset{\substack{\text { Heredia } \\
\text { Barban }}}{\text { B. }}$ & 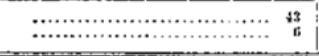 & $s$ & & \\
\hline
\end{tabular}

Figura 2. Tabla para la elección de los Supremos Poderes de la República de Costa Rica, 1825. Fuente: Costa Rica, Decreto LXIII, 13 octubre 1825, Colección de leyes, decretos, acuerdos y resoluciones que ha expedido la Legislatura del Estado, 1886, p. 166.

Puede que las juntas electorales fueran partidistas, pero en general fueron diligentes en documentar los desafíos y resolver los cuestionamientos de la ciudadanía de un votante. A veces desechaban información no deseada, como cuando las juntas en Costa Rica y Guatemala se negaron a considerar la evidencia de que algunos votantes jóvenes eran menores de edad (Guatemala Ciudad, 1821-1830, AGCA; Obregón, 2000) ${ }^{17}$. Pero había más burocracia en los libros que escándalos. El libro electoral de Sonsonate detalla las discusiones sobre las calificaciones de votantes e, incluso, si se debía celebrar o no las elecciones del diputado federal del distrito en 1826, porque la independencia nacional estaba en duda (Sonsonate, 1821-1830, Archivo Municipal de Sonsonate). En general, los miembros de las juntas parecían estar bien informados y dispuestos a implementar la ley si la situación lo requería. En las elecciones estatales de Guatemala en 1837, la junta electoral departamental de Salamá optó por elegir su diputado estatal a pesar de la ausencia de los electores de los distritos alejados de Petén y Cahabón. Los jueces de circuito argumentaron que los dos distritos deberían estar presentes para celebrar las elecciones, pero la junta argumentó que la mayoría de los electores estaban presentes, que Salamá carecía de representación en la asamblea anterior por la misma razón, y que el Congreso no dictaminó nada al respecto. Aunque algunos miembros de la junta boicotearon las elecciones en señal de protesta, la comisión de credenciales del Congreso admitió al ganador (Guatemala, 1837, AGCA, ff. 9-11). 
En general, como los ejemplos indican, cuando surgieron y se registraron de buena fe las denuncias de fraude, las juntas consultaron las leyes, las debatieron y, en gran medida, implementaron sus criterios. En las elecciones de Guatemala de diciembre de 1837, para elegir vicepresidente federal, juez de la Corte Suprema de Justicia y congresistas, el Congreso apoyó a la junta electoral departamental que rechazó los resultados de las votaciones del pueblo de San Juan Sacatepéquez, porque tres testigos afirmaron que el secretario había contabilizado mal los votos para que fuera él el "elegido" (Guatemala, 1837, AGCA, ff. 5-6v). Recurriendo a la constitución federal y a la ley electoral, la junta descalificó al elector y continuó con la elección. Sin embargo, el número limitado de votantes distritales y departamentales y los casos anuales en sí plantean algunas interrogantes: ¿indican una baja incidencia de problemas y, por tanto, un sistema electoral plenamente operativo, o una privación oculta del derecho de voto? ¿La amplia gama de problemas reflejaba un fraude sustancial o los caprichos de la aplicación de regulaciones en lugares con pocos registros o votantes alfabetizados?

Posiblemente el signo más claro de la afiliación centroamericana al sistema representativo es la participación de los votantes. En teoría, los ejecutivos fueron elegidos por períodos de cuatro años; pero los tribunales supremos, las asambleas federales y estatales y los "poderes/senadores conservadores" rotaban un tercio o la mitad de sus miembros anualmente, cada dos años o cada tres años. Las elecciones municipales se celebraban anualmente. Así pues, se produjo todo un intrincado ciclo de elecciones anuales. En realidad, el número de reuniones electorales a las que tuvieron que asistir los electores sobrepasó a las previstas en las constituciones. Las constituciones exigían que se celebraran reuniones populares un domingo determinado, seguidas de juntas de partido dos semanas o un mes después, y de juntas de departamento dos semanas o un mes después de esa fecha. De acuerdo con este calendario, un proceso electoral podía tardar entre uno y tres meses. Resulta interesante advertir que mientras algunos estados decretaron el final del año (noviembre y diciembre) para celebrar elecciones, otros optaron por realizarlas a principios de la primavera (enero y febrero), lo que supuso un proceso dilatado de recolección de boletas para los puestos federales (ver Tabla 1). En marzo de 1826, el Congreso Federal emitió un decreto, el Reglamento Electoral de la República Federal de Centroamérica, que aplicó un único calendario electoral para las elecciones federales en todos los estados (en Esgueva Gómez, 2006, pp.232-42). Dado que los electores eran elegidos por individuos para que los representaran en elecciones específicas, el sistema constitucional requería que los ciudadanos de un municipio participaran en elecciones estatales o federales, al menos anualmente. Los electores tenían que presentarse más a menudo, sobre todo porque los ciudadanos elegían no sólo a los electores de los distritos y departamentos, sino también a los que seleccionaban a los concejales municipales (Guatemala, Constitución de 1825, Art. 166; El Salvador, Reglamento de Jefes Políticos y Municipalidades, 1832, Art. 54-55, en Menendez, 1855, p. 167). 
TABLA 1

Calendario Electoral Oficial, Período Federal, 1824-1839

\begin{tabular}{|c|c|c|c|c|c|}
\hline & $\begin{array}{l}\text { JUNTA } \\
\text { POPULAR }\end{array}$ & $\begin{array}{l}\text { JUNTA DE } \\
\text { DISTRITO/ } \\
\text { PARTIDO }\end{array}$ & $\begin{array}{l}\text { JUNTA DE } \\
\text { DEPARTA- } \\
\text { MENTO }\end{array}$ & $\begin{array}{l}\text { SESIONES } \\
\text { DEL } \\
\text { CONGRESO * }\end{array}$ & CONSTITUCIÓN \\
\hline Federación & $\begin{array}{l}\text { 1er. domingo en } \\
\text { octubre }\end{array}$ & $\begin{array}{l}\text { 2do. domingo, } \\
\text { noviembre }\end{array}$ & $\begin{array}{l}1 \text { domingo, } \\
\text { diciembre }\end{array}$ & $\begin{array}{c}1 \text { marzo, } 3 \\
\text { meses }\end{array}$ & $\begin{array}{c}\text { 1824, Art 29, } \\
66,67\end{array}$ \\
\hline Guatemala & \multicolumn{3}{|c|}{ Mismas juntas, fechas, que el calendario federal } & $\begin{array}{c}1 \text { febrero, } 3 \\
\text { meses }\end{array}$ & 1825, Art 52 \\
\hline $\begin{array}{c}\text { El } \\
\text { Salvador }\end{array}$ & $\begin{array}{l}\text { 1er. domingo en } \\
\text { octubre }\end{array}$ & $\begin{array}{l}\text { 3er. domingo } \\
\text { en octubre }\end{array}$ & $\begin{array}{l}\text { 2do. domingo, } \\
\text { noviembre }\end{array}$ & $\begin{array}{c}2 \text { enero; } 60-90 \\
\text { días }\end{array}$ & 1824, Art 15,18 \\
\hline Honduras & \multicolumn{3}{|c|}{ Fechas federales para elecciones estatales } & & 1825, Art 14,15 \\
\hline Nicaragua & \multicolumn{3}{|c|}{$\begin{array}{l}\text { Fechas federales para elecciones estatales; elección } \\
\text { para el Jefe de Estado el día después de las } \\
\text { elecciones federales en la Junta de departamento }\end{array}$} & $\begin{array}{c}15 \text { de enero, } 3 \\
\text { meses }\end{array}$ & $\begin{array}{c}\text { 1826, Art. } 49 \\
78,101\end{array}$ \\
\hline Costa Rica & $\begin{array}{l}\text { 1er. domingo de } \\
\text { enero }\end{array}$ & $\begin{array}{l}\text { 3er. domingo } \\
\text { de enero }\end{array}$ & $\begin{array}{l}\text { 1er. domingo } \\
\text { de febrero }\end{array}$ & $\begin{array}{c}1 \text { marzo, } 3 \\
\text { meses }\end{array}$ & $\begin{array}{c}\text { 1825, Art } 27-29 \\
\text { Art } 49\end{array}$ \\
\hline
\end{tabular}

* Todos los congresos podrían extender las sesiones hasta 4 meses. Fuente: Las citas se agrupan bajo elaboración propia.

Por lo general, las juntas extraordinarias fueron convocadas tres o cuatro veces al año, en particular para renovar puestos. Muchas veces, aunque no únicamente, se reunieron para renovar puestos municipales que quedaban vacantes debido a renuncias por cuestiones de salud, compromisos comerciales o por servicios anteriores y por ascensos a puestos estatales o federales. En marzo de 1824, el abogado y alcalde primero de Ciudad de Guatemala, el Lic. Antonio Rivera, dimitió porque ya había sido miembro de la Diputación Provincial de Guatemala, de la junta de gobierno interina y de la junta preparatoria de la Asamblea nacional Constituyente, y dijo tener que dedicarse a la abogacía para sostener a su familia. Cuatro electores ofrecieron pagarle un estipendio para que se quedara en su cargo porque ningún otro individuo "merecía el apoyo del pueblo". Rivera rechazó la oferta por "indecorosa", pero permaneció hasta que fue designado miembro del poder judicial estatal un mes más tarde. Dos meses después, en junio de 1824, otros dos concejales, Manuel José de Lara y Manuel Beteta, ingresaron al juzgado de letras guatemalteco y renunciaron a su cargo municipal (Guatemala, 1821-1830, AGCA, ff. 21v-23, 26v). Este ritmo de elecciones y remplazos crónicos se institucionalizó en la época federal, con el resultado que se podía esperar: menos electores en cada sesión. En diciembre 1824, 
23 electores municipales de Guatemala se presentaron para la primera elección de concejales y dividieron sus votos de manera bastante equitativa: 14 a 9 en la mayoría de los casos. El mismo año, hubo sesiones extraordinarias en nueve ocasiones -los días 8 y 23 de enero, 1 y 28 de marzo, 2 de abril, 4 de junio, 19 de julio, 19 y 23 de septiembre- para reemplazar a los individuos que no aceptaron la nominación por haber sido elegidos a puestos estatales o federales (Ibidem, ff.29-39v)..$^{18}$ Al menos hasta 1850, tales renuncias eran típicas en las capitales políticas, como Antigua (Guatemala), Tegucigalpa (Honduras) y Sonsonate (El Salvador), probablemente más que en otros pueblos, según los libros electorales que muestran elecciones de reemplazo celebradas de enero a noviembre cada año, lo que significó un gravamen tanto para los votantes como para los elegidos. Esto podría sugerir que los gobiernos centroamericanos tomaban sus funcionarios de un grupo limitado de individuos educados y de orientación cívica que tenían que escoger entre servir dentro de puestos municipales, estatales y federales (Dym, 1997; Dym, 2006) ${ }^{19}$.

Tras documentar las múltiples reuniones de juntas electorales hasta la década de 1830 para elecciones locales, estatales y federales, se confirma la extensa participación ciudadana, aunque con una significativa variación en la participación según la elección. En Antigua, Guatemala, por ejemplo, entre 15 y 60 electores participaron en la selección de electores de partido en la década de 1820, para una población de 7.000 "españoles y mulatos" según datos de 1800 (Archivo Municipal de Sonsonate; Antigua, Archivo Municipal de la Antigua; Juarros, 1981[1808-1818], 48) ${ }^{20}$. La amplia variación sugiere un interés desigual según la naturaleza de la elección. Aunque el número de participantes en general cambió en cada evento, en Sonsonate, con alrededor de 4.000 residentes, los registros de votación de las décadas de 1820 y 1830 sugieren al menos entre 50 y 60 personas que participaron en las elecciones de comisarios, o sea, una participación estable durante un período con cambios políticos y disturbios dramáticos ${ }^{21}$. (Sonsonate, 1821-1830). En Guatemala, las elecciones estatales y federales de 1829 mostraron "elecciones populares" de 15 a 28 votos emitidos en cada una de las cinco juntas de departamento, los órganos electorales de tercer nivel. Estos resultados son llamativos y sugieren que, aunque relativamente pocas personas participaron en la elección directa de los funcionarios gubernamentales, hay signos de competencia por los cargos. Por ejemplo, aunque dos ciudades tan importantes como Guatemala y Totonicapán muestran casi unanimidad de votos, las tablas de elecciones por distrito revelan que la mayoría de los candidatos recibían votos en varios departamentos (Sonsonate, 1821-1830, Archivo Municipal de Sonsonate (AMS)). Por último, las actas electorales mismas ofrecen ideas de por qué había un interés sostenido en ellas: las sesiones de votación además de ser una oportunidad para emitir votos proporcionaban a los participantes la oportunidad de discutir reglamentos y políticas nacionales. Dicho esto, las mismas listas de votantes indican límites a la expansión de la ciudadanía o al compromiso político a través del sufragio. Los nombres de los votantes y de los miembros de la junta durante casi veinte años de gobierno republicano revelan una estabilidad asombrosa. 
En Sonsonate, los apellidos de ciudadanos activos del período colonial tardío como Villavicencio, Mencía, Rivas, Vega, Zea, y Orantes, entre otros, no solo continuaron, sino que ocuparon una plaza importante dentro de los votantes y electores hasta bien entrados en la década de 1830 (Sonsonate, 1821-1839, AMS).

Estos ejemplos específicos, aunque convincentes, plantean tantas preguntas como respuestas. Los casos analizados provienen principalmente de antiguas capitales de distrito y las preguntas que resta responder son si en las ciudades más pequeñas siguieron patrones similares o, si por el contrario, cambiaron los patrones en países con poblaciones indígenas más importantes que en estas ciudades ladinas o mestizas. Al menos un historiador guatemalteco, Julio César Pinto Soria, ha argumentado que las élites usaron el liberalismo para destruir la red de pueblos indígenas y su sistema de justicia interna; que los indios eran reacios a los consejos municipales elegidos porque cortaron su poder; y que la igualdad política y jurídica ofrecida por las constituciones fue una "igualdad ficticia" que las clases populares inmediatamente advirtieron y rechazaron (Pinto, 1997, pp. 5-6,23-27). La insistencia del proyecto liberal en la "ladinización", o hispanización, de los pueblos indígenas incluyó al régimen de Mariano Gálvez en Guatemala, que insistió en 1835 en el Estatuto de la Instrucción Primaria, del 31 de agosto de 1835 (Art. 67), que un indígena que no usara zapatos, una camisa con cuello, pantalones largos y un sombrero, no podría servir de regidor, alcalde, síndico o "ni otro alguno de la parroquia" (en Pinto, 1997, 13, n.21).

Cierta evidencia sustancial sugiere, al contrario de lo afirmado arriba, que los consejos de pueblos indígenas no solo continuaron reuniéndose, sino que influyeron en las políticas. El estudio de Sonia Alda Mejías (2004a) sobre los cabildos indígenas sostiene que, lejos de ser reaccionarias, las comunidades indígenas se adaptaron al sistema y también adoptaron nuevas instituciones políticas para lograr sus propios fines (pp.125-152,140,145-149). Por ejemplo, el sistema constitucional ofreció la oportunidad a los macehuales, o miembros de la comunidad, de presentarse y ganar las elecciones municipales, a veces yendo en contra de los principales, es decir, las élites que habían monopolizado las instituciones locales lo largo del período colonial (Alda, 2002, 2004b, pp.125-152,140,145-149). Los legisladores eran conscientes de las preocupaciones por la posible privación del derecho de voto de los plebeyos indígenas, aunque no estaban necesariamente facultados para impedir que se siguieran utilizando las "distinciones" tradicionales como criterio para las elecciones de "empleos consejiles" (Córdova en Asamblea Nacional Constituyente, 1824, f.24) ${ }^{22}$.

Por lo tanto, otra manera de analizar el proceso electoral no solo son las relaciones entre las comunidades indígenas y el Estado, un tema de frecuente interés para los y las historiadoras, sino como muestran Alda Mejías (2002) y Grandin (1997, pp.211-243, 216-229), la apropiación intercomunitaria de nuevas formas políticas para abordar las disparidades a nivel local. Además, como Taracena Arriola demuestra, algunas comunidades indígenas supieron influir en sus organismos representativos, tanto en el contexto nacional como en el estatal. En 1838, cuando 
las élites blancas del altiplano de Guatemala avanzaron un proyecto para formar un sexto estado centroamericano, Los Altos, representantes de pueblos indígenas, se reunieron para manifestar su oposición al proyecto. Según ellos, el proyecto incluía planes para recaudar impuestos sobre personas y no sobre las propiedades, es decir, consideraban que se quería fomentar un sistema que favoreciera económicamente a los terratenientes europeo-americanos. A lo largo de febrero y marzo, los municipios zutuhiles de San Pedro, San Juan, San Marcos la Laguna y Santiago Atitlán escribieron al gobierno guatemalteco para oponerse al sexto estado, que según ellos perjudicaría el comercio con Ciudad de Guatemala. En otro caso, cuando Quetzaltenango intentó recaudar impuestos en Santa Catarina Ixtahuacán (Sololá) y San Sebastián (Retahuleu), las aldeas convocaron cabildos abiertos y se negaron a pagar. Algunas comunidades de las tierras altas recurrieron al gobierno de Guatemala en busca de apoyo, tras comprobar que el Estado solo advirtió quejas contra el proyecto de Los Altos por "súbditos de otro [gobierno] independiente". Es decir, los municipios indígenas primero buscaron resolver el conflicto respetando las instituciones representativas tradicionales y nuevas. Al decidirse por la consulta y no por el conflicto, los indígenas escribieron primero directamente a las autoridades de Los Altos, luego buscaron la ayuda de Guatemala, y confiaron tanto en sus representantes en el Congreso como en los cabildos abiertos para organizar su respuesta. Solo cuando ambos gobiernos estatales se mostraron sordos a sus quejas, se unieron en una insurrección para forzar el cambio (Taracena, 1997, pp.310-15, 315).

A pesar de la expansión de las instituciones y de las prácticas electorales durante el período federal, las disposiciones que otorgaban a las asambleas legislativas la facultad de decidir en las disputas electorales no siempre respetaron la voluntad del pueblo expresado en sus votos. Había precedentes. La Constitución de Estados Unidos de 1787, en el Art. II, Sección 1, y la 12ª Enmienda, estipuló que el Congreso seleccionaría un presidente si ningún candidato obtenía una mayoría absoluta de votos, lo cual sirvió, sin duda, de modelo para los legisladores centroamericanos. Si bien en Estados Unidos esta cláusula rara vez se invocó ${ }^{23}$, las asambleas centroamericanas recurrieron reiteradamente a cláusulas similares para "seleccionar", "elegir" o "nombrar" a los jefes de estado. A nivel federal, el caso más prominente de anulación legislativa del voto popular ocurrió con la primera elección del ejecutivo federal en 1825. En las primeras elecciones federales de Centroamérica, José Cecilio del Valle y José Manuel Arce recibieron, respectivamente, 41 y 34 votos de 79 distritos electorales aprobados por los congresos federales, después de lo que el historiador Ralph Lee Woodward Jr. (1993) ha descrito como una "campaña enérgica” realizada a través de "un flujo de volantes políticos y periódicos partidistas" (p.29). Con 82 territorios electores y 82 votos posibles, la Asamblea Constituyente determinó que Valle no había recibido una "mayoría" como lo requería la Constitución, por lo que seleccionó a Arce a pesar de que el Congreso contó sólo 79 papeletas y podría haber considerado 41 como la mayoría. Valle, comprensiblemente, rechazó el cargo de vicepresidente. El análisis contemporáneo de Alejandro Marure comprueba la 
influencia de los partidos políticos en la decisión federal, con un consenso de liberales y conservadores sobre la elección de Arce después que indicara que no se involucraría en buscar que se estableciera un obispado en su estado natal, San Salvador, independiente del arzobispado de Guatemala (Marure, 1960 [1837], pp.241-3).

De acuerdo con este precedente, las asambleas legislativas a menudo seleccionaron a los líderes nacionales, a veces, en contra de los votos expresos. En el otoño de 1824, la asamblea estatal guatemalteca contabilizó los votos para las primeras elecciones de jefe de Estado. Al descubrir que ningún candidato reunía la mayoría de votos en la elección popular, la asamblea nombró a Juan Barrundia y Cirilo Flores, respectivamente, como jefe y vice-jefe (Marure, 1960 [1837], p.198). Ethel García Buchard (2008) ha comprobado un caso paralelo en la selección del primer jefe y vice-jefe por parte de la asamblea constituyente hondureña (p.3). El estudio de Obregón (2000) sobre las elecciones presidenciales costarricenses en el siglo XIX destaca múltiples ejemplos de "selección" legislativa de candidatos presidenciales que prevalecieron sobre los votos populares, en gran parte, debido a disputas generadas sobre el significado de "pluralidad" o "mayoría" necesaria para ganar. Las legislaturas también podían deponer a los ejecutivos. Avendaño (2007) señala que en 1826 la Asamblea Legislativa de Nicaragua usó su facultad para "separar del comando" a los dos primeros jefes de estado. En los años siguientes, esta Asamblea también eligió al presidente cuando las elecciones no alcanzaron una mayoría (pp.67-8, 76).

Dado que los poderes legislativos contaban las papeletas no solo para los puestos ejecutivos sino también para los poderes judicial y legislativo, también podían influir en el proceso de selección de los miembros de estas instituciones. Es decir, la selección legislativa de los funcionarios estaba más profundamente generalizada si se extiende el enfoque más allá de las elecciones del poder ejecutivo. Ya en 1825, el Congreso Federal, en su Orden 193 (AGCA) rectificó un error de sus miembros, que habían declarado vencedor para el puesto de juez en la corte suprema de justicia a Manuel de la Cerda, quién ya había prestado juramento de su cargo. Los congresos también influyeron en las elecciones a través de comisiones para examinar las credenciales de los nuevos congresistas, es decir, durante la aprobación o el rechazo de los resultados de las elecciones. Las comisiones revisaron docenas de casos para cada sesión y aprobaron la mayoría de las credenciales de inmediato. Sin embargo, algunos casos fueron problemáticos. Cuando en 1829 las deudas del recién electo diputado José Valero plantearon dudas sobre su habilitación como ciudadano y elegibilidad, la comisión electoral del Congreso de Guatemala no estuvo de acuerdo sobre cómo evaluarlas (AGCA, f. 2v). A pesar de poder influir en este y otros asuntos, las comisiones reconocieron sus límites. La comisión del congreso de Guatemala del mismo año determinó que carecía de las facultades necesarias para evaluar los actos electorales del departamento de Totonicapán, tras conocerse que "los indígenas de Momostenango se habían negado a votar hasta que recibieron a su rey" (AGCA, 10v, para. 5). La última potestad del poder legislativo era examinar las elecciones locales, lo que también podría 
tener complicadas ramificaciones. Así pues, cuando Nicaragua se encontraba en una guerra civil en 1834 y la legislatura, con sede en León, creyó que las actas de varios municipios de Granada se quejaban de "intrigas y opresiones" en los procedimientos electorales, emitió un decreto el 3 de diciembre por medio del cial anuló las elecciones y ordenó a nuevas, y posiblemente más afines, juntas electorales que repitieran las elecciones (en Esgueva, 2006, pp.275-6).

Estos ejemplos destacan el importante papel de las asambleas legislativas y de sus comisiones en la confirmación o rechazo de las elecciones populares, así como en la elección o destitución de jefes de estado. También, muestran la confusa gama de cuestiones que podrían influir en las elecciones populares, sin relacionarse con la coerción y que, sin embargo, potencialmente perturbaron los procesos democráticos. Por lo demás, abundan las pruebas que revelan la invocación selectiva o el total desprecio de los requisitos legales, como en 1826, cuando el grupo que controlaba las comisiones legislativas de Guatemala autorizó la sustitución de todos los miembros del consejo conservador, en lugar de la mitad, para tratar de aumentar su representación en ese órgano. Sin embargo, como observó años más tarde Alejandro Marure (1960[1837]) sobre el sufragio, "a pesar de los resentimientos que engendraron en los ánimos por los grandes altercados [en los gobiernos federal y estatal] las cosas siguieron con bastante regularidad" (pp.253-5). La evidencia documental respalda tanto la existencia de disputas políticas acaloradas como la celebración de elecciones regulares.

El papel de las asambleas legislativas en los procesos políticos y electorales requiere una mayor exploración, dada la centralidad adquirida por las legislaturas en los nuevos ordenamientos constitucionales. La descripción del papel del congreso, por ejemplo, se antepone al de los poderes ejecutivos en cada constitución, desde Cádiz en 1812, en adelante; los capítulos que establecieron cuerpos legislativos anteceden a los del poder ejecutivo en las constituciones de Estados Unidos (1787), España (1812) y de Centroamérica de los 1820 y 1830 . La mayoría de las constituciones otorgaron explícitamente a las asambleas estatales y federales un margen de maniobra sustancial para aprobar, e incluso elegir, a las autoridades ejecutivas. Sin embargo, si bien los pronunciamientos de las ciudades y los representantes que superaron el proceso electoral son objeto de un serio escrutinio (Alda, 2004a, p.115-142), los y las historiadoras han pasado por alto, en gran medida, el examen de los actos legislativos. Eso se denota en un simple ejemplo: la decisión tan relevante de la asamblea legislativa de Costa Rica, en abril de 1829, de separarse temporalmente de la federación "mientras se restableciera el orden federal constitucional" (Obregón, 2000, p.80).

Finalmente, algunas prácticas políticas del Antiguo Régimen continuaron en Centroamérica durante la época federal, a pesar de la implantación de una estructura jurídica y política constitucional. Las prácticas de petición y negociación con las autoridades imperiales, "obedezco pero no cumplo", no desaparecieron y contribuyeron a que el nuevo sistema funcionara cuando fallaron los mecanismos oficiales. Los municipios conservaron su papel de intermediarios entre las comunidades y el gobierno estatal, al utilizar con frecuencia las consultas, peticiones e incluso 
pronunciamientos para influir en las políticas y contribuir al ascenso y caída de los gobiernos (Dym, 2007, pp.210-3, 234-41). En 1826, por ejemplo, cuando el primer jefe de estado de Nicaragua, Manuel Antonio De la Cerda, fue despedido por la asamblea legislativa al ser calificado de déspota, varios municipios emitieron actas para llamarlo nuevamente al poder. Cuando dos seleccionados por la asamblea para el puesto de jefe político entraron en guerra, De la Cerda prestó su juramento frente al cabildo de Managua en lugar de hacerlo ante la Asamblea, en contra de lo mandado por la costumbre y la constitución (Alda, 2004a; Avendaño, 2007, pp.68-9).

\section{ELECCIONES REPUBLICANAS, 1838 -CA. 1850}

El fracaso de la unión política centroamericana marca la ruptura legal y práctica con la gobernanza democrática basada en las innovaciones de Cádiz. La mayoría de las nuevas repúblicas redactaron constituciones nuevas poco después de separarse de la federación, lo que permite considerar la evolución de las ideas sobre las elecciones después de la independencia. Nicaragua (1838), Honduras (1839), Costa Rica (1841) y El Salvador (1841) convocaron asambleas constituyentes cuyas nuevas cartas magnas, en vigencias hasta finales de la década de 1840, iniciaron un período de gobierno conservador ${ }^{24}$. Guatemala, la excepción, no remplazó su constitución originaria hasta 1851, escrita para permitir la elección de por vida del presidente Rafael Carrera, quien gobernó siguiendo tres leyes fundamentales. Estas constituciones y leyes estatales reflejan algunas "lecciones aprendidas" de los primeros intentos de gobierno representativo, y generalmente se consideran respuestas "conservadoras" a los experimentos liberales ${ }^{25}$. La tensión entre las instituciones democráticas y las prácticas antidemocráticas, como los golpes de estado, cerró, en gran medida, el experimento en democracia a nivel federal, y dejó un legado mixto para las repúblicas centroamericanas separadas.

Después de separarse de la federación, los gobiernos centroamericanos continuaron declarándose "republicanos, populares y representativos", pero las constituciones de fines de la década de 1830 instituyeron cambios importantes. Primero, el "cuarto poder" fue reemplazado en la mayoría de los estados por un congreso bicameral; juntas de distrito seleccionarían diputados y cada junta de departamento elegiría dos senadores (Constituciones de: Nicaragua, 1838, Arts. 49, 51, 91, 99; Honduras, 1839, Arts. 17, 92; Honduras, 1848, Art. 15; El Salvador, 1841, Arts. 2, 13). En segundo lugar, por el temor a poderes ejecutivos fuertes, se redujeron los períodos presidenciales a dos años sin posibilidad de más reelecciones. Tercero, la legislación especificaba como condición pertenecer a una localidad para aspirar a puestos locales (Constituciones de: Nicaragua, 1838, Art. 132; Honduras, 1839, Art. 46; Honduras, 1839, Art. 47; El Salvador, 1841, Art. 44; Costa Rica, 1844, Art. 128).

Lo más importante para este estudio, el sistema de elecciones indirectas, introducido en la Constitución de 1812, fue, en gran medida, descartado. Nicaragua, El 
Salvador y Honduras adoptaron elecciones directas para la mayoría o la totalidad de los cargos ejecutivos, legislativos y judiciales estatales (Constituciones de El Salvador, 1841, Art. 10; Nicaragua, 1838, Art. 54) ${ }^{26}$. En contraste, Guatemala se inclinó abiertamente por modelos coloniales entre 1839 y 1845, introdujo restricciones en los derechos políticos, incluso el de votación, y aumentó las calificaciones para ser elegible. La Ley 76 de 1839 retuvo elecciones indirectas y la Ley 73, que organizó las autoridades judiciales del estado, no solo retomó los títulos judiciales de origen colonial de regente y oidor, sino que empoderó a la legislatura y no a las juntas electorales para seleccionar a los juristas entre abogados con 5 años o más de experiencia (Árts. 2 y 4). Esta profesionalización de la judicatura, aunque es posible interpretarla como una reducción de los derechos populares, se asemeja más a un esfuerzo para garantizar que personas aptas ocuparan esos puestos.

En la práctica, hubo significativas continuidades que socavaron la elección popular de figuras nacionales. A pesar de la inestabilidad política del período federal, o debido a ella, las asambleas constituyentes determinaron que sus congresos y senadores sucesores continuarían haciendo nombramientos provisionales e, incluso, algunos permanentes. En 1838, la Constitución de Nicaragua establecía que, en ausencia del ejecutivo, la Cámara de Diputados "nombraría" a un senador para su reemplazo temporal; si se necesitaba un sustituto permanente y quedaba más de la mitad del período original, los congresistas "elegirían" al nuevo titular entre los que habían recibido votos en las

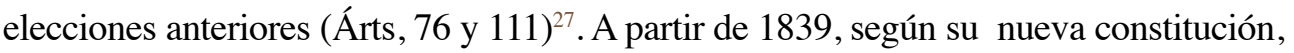
la Cámara de Representantes de Honduras podría "sortear" tres suplentes seleccionados entre los candidatos presidenciales para asumir el cargo "en caso de impedimento del Presidente" (Árt. 41). Los periódicos salvadoreños de la década de 1840 confirman la continuidad y aceptabilidad de la práctica de selección legislativa ${ }^{28}$.

Tanto Guatemala como Nicaragua promulgaron leyes abiertamente excluyentes con respecto a los ciudadanos indígenas. El derecho de las comunidades indígenas a elegir su propio municipio era limitado (al menos en el papel), mientras que (tanto en la teoría como en la práctica) aumentaron las oportunidades para la venta de tierras ejidales a propietarios privados e individuales (Alda, 2002). Costa Rica adoptó la misma política en 1849, al disolver los municipios indígenas y privatizar la tierra disponible para el cultivo de café (Molina, 1991, pp. 304-305). Sin embargo, como lo demuestra una investigación preliminar de fuentes de archivo, dicha legislación no fue necesariamente eficaz. La evidencia documental de la década de 1860, una generación después de su implementación, muestra su debilidad. Cuando en 1862, las aldeas indígenas de Nicaragua usaron su derecho de protesta, al citar 300 años de privilegios (regalías), el Senado permitió que al menos un pueblo solicitante eligiera a sus propios alcaldes y regidores, de acuerdo con la legislación colonial. Esta decisión sentó un precedente en el cual las comunidades indígenas y las autoridades nacionales aceptaron los principios del derecho imperial y la negociación. En años posteriores, como lo muestra Avendaño, los “cabildos indígenas" continuaron con la práctica de interpelar al jefe departamental que, a su vez, negoció especialmente sobre temas de privatización de tierras 
(Avendaño, 2007, pp.88-91). Por lo tanto, la eliminación de la municipalidad indígena en la práctica parece haber estado fuera del alcance del gobierno, aunque la reducción de tales pueblos a su estatus político pre-independentista parece que funcionó bien como estategia para mantener la paz.

Es posible suponer que el derecho de petición o reclamo sirvió a las comunidades indígenas en toda América Central (Grandin, 1997, 211-43, esp. 216 y 229). La violencia y las disputas que estallaron más allá de las instituciones estatales con frecuencia enfrentan a las comunidades indígenas entre sí mismas y no en contra de los terratenientes criollos o ladinos. Investigaciones adicionales deberían confirmar, como lo expresó Avendaño (2007), si los “ciudadanos" indígenas fueron relegados esencialmente al estado de "vecinos", sin derecho de participar en procesos electorales provinciales o nacionales como ciudadanos (p.89). Alda Mejías y Avendaño no analizan las listas de votantes y electores para identificar la participación, o no, de indígenas en las elecciones nacionales. A pesar de eso, esas autoras sí dan evidencia sobre su influencia en la política nacional y en cargos superiores. Dado que la constitución nicaragüense de 1838 declaró que aquellos que vivían en una población con menos de 300 residentes necesitaban organizar una junta popular para votar en el pueblo más cercano, una disposición que se remonta a las primeras constituciones centroamericanas, es posible que las listas electorales, ya fueran medianas o de gran tamaño, podrían incluir votantes indígenas (Art. 67). Sin evidencia sólida, es difícil llegar a conclusiones verídicas. Aun así, casos como los proporcionados por Grandin, Avendaño y Alda Mejías abogan por una comprensión más matizada de la vida política y participación electoral de las comunidades indígenas, con sus propias divisiones internas de élites y plebeyos privados de sus derechos.

Aunque solo se establecieron partidos políticos formales en América Central en las décadas posteriores, las décadas de 1830 y 1840 demuestran el reconocimiento de la coordinación entre los votantes. En Nicaragua, la ley electoral de 1838 estipuló tres días para la realización de elecciones, de 9 a.m. a 6 p.m; la votación era oral e individual. Sin embargo, la ley permitió explícitamente que un votante llevara su voto escrito en cédula "para gobierno del que vota". Dicha votación no podía sustituir el voto oral, ya que la ley especificaba que el votante "design[e] de palabra" el nombre del que elija, pero mostraba conciencia y aceptación de alguna organización y discusión preelectoral (Art. 28, y 40, en Nicaragua, 1867, pp.403 y 404). Queda por estudiar el impacto de permitir cédulas, además del papel electoral de los periódicos y panfletos, en los procesos de influencia en el sufragio.

Otro factor fue que las municipalidades operaron siempre con autonomía cuando los gobiernos estatales y federales se tambalearon, al reclamar un derecho comunitario a decidir la lealtad, en lugar de aceptar la soberanía estatal y expresar su voz política solo a través de representantes electos. Los referendos municipales, invocados en tiempos de vacíos de poder estatales o federales, hicieron poco para desalentar tales actos. El 14 de febrero de 1845, el periódico El Salvador Rejenerado abrió con una sección denominada "pronunciamientos," que incluía actos de 10 municipios que agradecían al 
Vicepresidente por derrocar al presidente Francisco Malespín; el único "voto" exigido por las ciudades fue poner sus actos en manos de una asamblea legislativa recientemente convocada para dar a conocer su apoyo (Taracena, 1995). Tal sentido de autoridad también fue invocado en las relaciones entre ciudades. Cuando Tegucigalpa recibió el aviso de la ciudad vecina de Danli, en 1845, de que esta había revocado su pronunciamiento y volvía a ofrecer su lealtad a Honduras y no a Nicaragua, Tegucigalpa acogió con beneplácito la decisión y respondió que era "altamente loable y placentero el que ese cuerpo municipal haya de alguna manera salvado su equivocación y vuelto a su deber obedeciendo a nuestro supremo gobierno" (Ayuntamiento de Tegucigalpa, 1845). Por lo tanto, incluso cuando los gobiernos pasaron a elecciones directas y votaciones individualizadas, las ciudades grandes y pequeñas persistieron en exponer los intereses de su comunidad directamente ante los mandatarios.

\section{CONCLUSIÓN}

En 1850, el novelista y estadista guatemalteco José Milla, citado en un artículo de Woodward (2001), propuso en un editorial que el sistema electoral federal fue "llamado indebidamente popular" y "odiado por las masas y las clases respetables de la sociedad" por su explotación de indios analfabetos que ignoraban las consecuencias de su voto. Como sugiere la discusión anterior, esta opinión despectiva puede representar valores decimonónicos y no el compromiso popular o de la élite con la política electoral en el cuarto siglo después de la independencia. Desde 1809 hasta la época de Milla, se llevaban a cabo, a un ritmo alucinante y de manera regular, elecciones locales, distritales y departamentales para puestos en los consejos municipales, en el poder judicial, las legislaturas y el poder ejecutivo, las cuales incorporaron una constelación de cambios en las leyes y reglamentos electorales así como cambios irregulares en el liderazgo de los gobiernos estatales y federales. El proceso electoral continuó a pesar de las guerras regionales y de la inestabilidad de los gobiernos estatales y federales. Concurrieron muchas personas (y muchas veces las mismas, década tras década) a votar y ser elegidas, para participar de forma regular y activa, entre 1808 y 1839, en el ensayo del gobierno republicano. En cierto modo, fue una transición exitosa.

Sin embargo, esta experiencia centroamericana de implementar regímenes políticos y jurídicos democráticos podría haber provocado desagrado entre los ciudadanos por estar marcada por las características descritas en este artículo. Primero, para la mayoría de ciudadanos, aunque los gobiernos demandaban una inversión importante de su tiempo y atención, la votación solo les permitía elegir directamente a las autoridades locales y miembros de las juntas electorales de su distrito. Ya sea que se crea en el valor de este sistema de "colegio electoral" o no, es importante indicar que, durante la federación, gracias al sistema 'selectoral', la mayoría de ciudadanos que ejercían sus derechos no podían ni votar, ni recomendar a un candidato de alto cargo. Los legisladores federales y estatales, con experiencia en el 'experimento 
de Cádiz', planificaron una transición gradual de una estructura constitucional monárquica a una republicana. La legislación y los debates a menudo reflejan esfuerzos racionales, racionados y de buena fe para combinar lo viejo con lo nuevo. Al pasar de la selección del azhar a elecciones indirectas que privilegiaron candidatos entre las elites, el caso centroamericano parece confirmar en Hispanoamérica la importancia de la selección de gobernantes en sistemas representativos, identificados por Bernard Manin (1996) desde los griegos y romanos hasta los regímenes establecidos en Inglaterra, Francia y los Estados Unidos modernos.

Pero, la consecuencia distinta - $\mathrm{O}$ al menos no considerada por Manin-, como previó el congresista federal en 1823, y el aprendizaje que conllevó, amargaba, alienaba, o cansaba a los más aptos para votar y servir. Despreciaron la dificultad de implementar un sistema cuyas complejidades multiplicaron con el número de puestos a llenar en gobiernos republicanos y representativos. Además, no anticiparon que el uso frecuente del sistema que otorgaba a las legislaturas un campo amplio para nombrar a las personas preferidas por los congresistas, sin insistir en respetar los resultados de las elecciones, daría lugar a cuestionamientos de legitimidad que, en el peor de los casos, animaron a insurrecciones. Así, la novedad de hacer electivas a las autoridades ejecutivas, legislativas y judiciales por procesos no solamente indirectos sino selectorales tenía un costo alto que no se anticipó suficientemente.

Por alejamiento o conveniencia, junto a estas nuevas instituciones, los métodos tradicionales de expresión política continuaron en vigencia, como las peticiones dirigidas a legislaturas y ejecutivos y los pronunciamientos de consejos municipales. Lo que Romana Falcón ha llamado el "arte de la petición" para el México decimonónico tuvo raíces coloniales y se manifestó también en América Central después de la independencia. Tales expresiones colectivas de opinión política o protesta pueden ser el reflejo de múltiples formas de representación que probablemente contribuyeron, y a veces obstaculizaron, a la construcción del estado-nación. Esas formas de representación podrían considerarse como una faceta de los primeros procesos centroamericanos de democratización, que han sido explorados productivamente por Avendaño Rojas, Obregón y Alda Mejías, entre otros, y merecen una mayor exploración teórica y de archivo.

En general, las fuentes narran los esfuerzos concertados en desarrollar un sistema político que permitiera "el goze del derechos" del ciudadano individual y, a la vez, respetar una distribución tradicional del poder político, mantener a los ayuntamientos como organismos políticos y administrativos importantes y preservar el control del ejecutivo sobre el nombramiento de gobernadores departamentales. Algunos experimentos de la era federal no funcionaron, como crear un "cuerpo conservador" que parecía cruzar la forma y las funciones de un senado y un consejo de estado, o aplicar el complejo y lento sistema electoral de Cádiz a tres ramas separadas de gobierno. Ante tales fracasos, los estados centroamericanos, a partir de mediados del siglo XIX, rechazaron el complejo sistema 'selectoral' y adoptaron una legislatura bicameral "estándar" y aumentaron el número de puestos elegidos con elecciones populares 
directas. Lo remarcable es que, en lugar de reducir la responsabilidad ciudadana frente a las cámaras legislativas y los ejecutivos, la ampliaron. Al final, el legado democrático de esta era de revoluciones fue mixto: la adopción de instituciones representativas en la Centroamérica independiente fue un esfuerzo sincero que produjo elecciones relativamente libres a nivel local y que mostraron interés y competencia popular, pero las prácticas coloniales junto con el abuso del cargo o las acciones extralegales a nivel estatal y federal mostraron tanto las desventajas como los beneficios de un sistema representativo. Estos procesos y contradicciones estructurales y orgánicas contribuyeron a delinear los caminos problemáticos que siguieron.

\section{NOTAS}

1 En la Centroamérica decimonónica, la acepción ‘ladino' podía indicar una persona de herencia mixta (europeo, indígena, africano) y/o una persona de cultura hispánica (hablar, vestir).

2 Hay una larga y excelente literatura sobre el tema, liderada por autores europeos e iberoamericanos. (Quijada, 2005, pp.61-86; Guerra, 1992, y 1998; Rodríguez J, 1994; Stoetzer, 1979; Chiaramonte, 2004, pp.563-86; Annino, 1996 y 2003).

3 La literatura sobre la transición entre colonia y estado, o a la independencia, que en muchos casos toca el tema, es más amplia. Entre otros, véanse los trabajos de Lujan Muñoz, Meléndez Chaverri, Pinto Soria, Rodríguez, Taracena Arriola y Wortman.

$4 \quad$ Hasta el último cuarto del siglo, las historias legales y electorales de la América Central eran pocas. El bicentenario de la independencia iberoamericana llamó la atención sobre el trabajo de François Xavier Guerra, Antonio Annino, Jaime E. Rodríguez O. y otros, e inspiró a toda una generación de investigadores. Los trabajos del jurista García Laguardia, 1971 y 1980, son excelentes introducciones al pensamiento político, aunque con menos atención a la cultura y vida política.

5 Uso el neologismo porque me parece que un proceso 'selectoral' describe la combinación de selección de candidatos o funcionarios después de elecciones que no se tratan de definitivas. Es un sistema que se base en privilegiar la elección como la forma oficial de designar gobernantes, mientras que existe y se utiliza la selección entre candidatos para resolver incertidumbres.

6 Véase Piccato (2010) para una bibliografía de obras importantes sobre la esfera pública en Iberoamérica hasta 2010.

7 Véanse, para las elecciones llevadas a cabo en Centroamérica; 14 de julio (Chiapas), p.114; 27 de julio and 3 de octubre (Guatemala), p.140 y pp.265-6; 7 de agosto (Cartago), p.170; 10 de octubre (León), p.270-1; 10 de noviembre (Granada), p.313; 1 de diciembre (San Salvador), p.371.

8 Dardón Flores (2008) encontró que seis de los once electores de la parroquia de Antigua, Sacatepéquez Guatemala, eran alcaldes de las aldeas.

9 Woodward imagina los orígenes de los partidos políticos en estas elecciones municipales sin mencionar la formación de organizaciones formales. 
10 Belaubre (2011) ofrece una metodología llamativa para imaginar la ciudadanía de los que observan y no actúan directamente en las actas independentistas en ciudad de Guatemala.

11 Francia en su constitución de 1791 estableció un 'sénat conservateur' que sirvió de modelo para los legisladores centroamericanos.

12 Como en las demás nuevas repúblicas, ni las mujeres ni los menores de edad se beneficiaron con el título de ciudadano. Con eso dicho, Centroamérica en la década de 1840 pronto extendió los derechos políticos, quisieran o no, a los extranjeros radicados y casados con mujeres de la región, en lugar de expatriarlas (Dym, 2009, p.45-46)

13 Hay una bibliografía notable sobre el papel de las mujeres en la independencia hispanoamericana, además de estudios sobre la adquisición de derechos civiles y políticos que empiezan en la segunda mitad del siglo XIX. Los ensayos recientes de Erika Pani (2006) y Sarah Chambers (2017) ofrecen un punto de partida para la bibliografía hemisférica. Eugenia Rodríguez, en su análisis de más de 800 estudios de las mujeres y de género en Centroamérica y Chiapas entre 1957 y 2015 , encuentra que el enfoque sobre la mujer y el proceso electoral cubre más bien el siglo XX que el siglo XIX (2019, p.156); la participación decimonónica femenina directa e indirecta sigue siendo un campo bastante abierto y muy interesante para investigación en Centroamérica.

14 Solo Costa Rica estableció procesos distintos para elecciones federales y estatales.

15 Marure (1960 [1837]) describe el debate sobre las instituciones estatales entre federalistas (conservadores) y centralistas (liberales). También hubo 'largas y acaloradas discusiones' sobre la manera de elegir jueces; "la excesiva extensión que se daba al derecho electoral" y los limites en el poder ejecutivo con los excesos del poder legislativo.

16 Avendaño Rojas sugiere que hubo concurrencia para servir en las juntas electorales, y que los ganadores influyeron en las elecciones. La propuesta es muy llamativa pero no ofrece citas ni ejemplos concretos en su libro que puedan confirmarla.

17 Al leer libros de elecciones para estos pueblos, no encontré problemas en la mayoría de casos. En 1822, un regidor dijo haber recibido una carta anónima que denunciaba a un elector como menor de edad e inelegible para servir; la junta discutió y rechazó el alegato.

18 Según Art. 166 de la Constitución de Guatemala (1825), los ciudadanos elegían a los electores, quienes anualmente elegían a los miembros del ayuntamiento. La constitución no especificó un número fijo o una proporción para decidir el número de electores.

19 Las actas municipales y los registros electorales sobrevivientes, que cubren los años de 1824 a 1850, enumeran concejales ausentes, renuncias y nombramientos para cargos estatales desde directores de carreteras hasta mandatarios y jueces. Las fuentes, elecciones, son de la AGCA, Archivo Municipal de Sonsonate, ANH, y Archivo Municipal de Tegucigalpa. Véase Dym, 2006, Apéndice G, es una tabla de puestos estatales y federales ocupados por miembros de estos cabildos en 1821,1830 y 1840 .

20 Sonsonate, Libros de elecciones, 1822-1830, Archivo Municipal de Antigua, Guatemala; Juarros, 1981[1808-1818], 48.

21 Ibid. Juarros, Ibidem, 19, indicó 441 Españoles, 2795 ladinos and 185 Indios ca.1800. En 1853, según Estadistica de la Ciudad de Sonsonate, San Salvador, Imprenta del Triunfo, 
1853, la municipalidad tenía 4472 residentes en tres cantones electorales. Según leyes salvadoreñas de 1832 y las bases demográficas de la Constitución de 1812, Sonsonate merecía alrededor de 40 electores.

22 En 1824, José Francisco Córdova pidió que la Asamblea examinara las "actas de elección” de los pueblos de San Francisco y San Cristóbal (Totonicapán) para estos fines.

23 En 1825, la Cámara de Representantes eligió a John Quincy Adams como presidente.

24 Honduras adoptó dos constituciones adicionales antes de $1870(1848,1865)$; El Salvador, una (1864); Nicaragua, dos $(1854,1858)$ y Costa Rica, seis $(1841,1844,1847,1848,1859$, y 1869$)$.

25 El estudio de Alda (2004a) ofrece una excepción al ver el período por medio de la diferencia entre liberales y conservadores; ella enfatiza las tensiones en el interés de gobiernos centralistas en consolidar poder, y el respecto para los intereses de comunidades y regiones.

26 La constitución de Nicaragua de 1838 otorgó la elección en tres grados únicamente para los senadores; para otros puestos, incluso para el jefe de estado y la legislatura, había elecciones en dos grados; Costa Rica (1844), Arts. 53, 97, 120.

27 Las dos cámaras eran responsable de calificar votos para el 'director del estado' o, cuando no era popularmente electo, nombrarlo, y nombrar los funcionarios federales dados al estado (Art. 110).

28 Hay varios ejemplos en Taracena, 1995; véase especialmente El Iris Salvadoreño nos. 17 y 18,1837 , que publican decretos que indican los votos populares y legislativos para miembros del gobierno estatal.

\section{REFERENCIAS}

\section{Fuentes de Archivo}

\section{Archivo General de Centroamérica (Guatemala Ciudad, Guatemala)}

A1.2 Leg. 44, Exp. 1136. Caso de Ambrosio Sánchez, 24 de julio de 1820.

A1.2, Leg. 2188, Exps. 15734 y 15735, Guatemala Ciudad, Libro de Cabildo 1809.

B Leg. 73, Exp 2121. (1822). Carta del indio natural de Chimaltenango, Juaquín Cham, al Jefe Político Superior, 19 de febrero.

B Leg. 91, Exp. 2453, f. 1 (1823). Centroamérica, Asamblea Nacional Constituyente (ANC). Proposición, 17 de julio, derechos para extranjeros y los de origen africano, nacido libres o manumisión.

B Leg. 91, Exp. 2461. (1824). Centroamérica, ANC, Proposición de José Francisco de Córdova, 4 de marzo, f. 14. 
B Leg. 91, Exp. 2465, f. 4 (1824). Centroamérica, ANC, Proposición, 8 de julio.

B Leg. 542, Exp. 10125 (1845). Guatemala, Ciudad de Guatemala, Libro de Cabildo, Sesión Ordinaria 84,23 de diciembre.

B Leg. 1489, Exp. 15717. (1821-1830). Guatemala, Ciudad de Guatemala Ciudad, 1821-1830. Capitán General Antonio González Mollinedo y Saravia, Guatemala del 30 de abril de 1809, con Junta Central, Real Orden, 22 de enero de 1809.

B Leg. 4126, Exp. 29708, f 28. (1825). Congreso Federal de Centroamérica, Orden 193, 25 de julio.

C1 Leg. 111, Exp. 3223, f. 2v. (1829). Guatemala, Segunda Legislatura, Actas públicas de sesiones ordinarias de 30 y 31 julio y 6 de diciembre.

C1 Leg. 111, Exp. 3223, f. 10v. (1829). Guatemala, Segunda Legislatura, Actas publicas... 8 de agosto.

C1 Leg. 111, Exp. 3261. (1829). Guatemala, Elecciones populares del Estado de Guatemala para el año de 1829.

C1 Leg. 114, Exp. 3251, 3258, 3457. (1829) Elecciones populares del Estado de Guatemala para el año de 1829.

C1 Leg. 204, Exp 5479. (1837). Guatemala, Elecciones.

C1 Leg. 204, Exp. 5479. (1837). Guatemala. Poderes: Credenciales de diputados y suplentes,

\section{Archivo General de Indias (Sevilla, España)}

Guatemala 629. (1814). Capitán General/Jefe Político Superior Bustamante al diputado de Quetzaltenango José Cleto Montiel, 31 de enero de 1814.

\section{Archivo Historico de la Nobleza (Valencia, España)}

C.2, D. 38, España, Junta Central,Real Orden, 22 de enero de 1809

C.2, D. 39, España, Consejo de Regencia (España), Decreto, 14 de febrero de 1810.

\section{Archivo Municipal de Antigua (Antigua, Guatemala)}

Libros de Actas y Elecciones, 1822, 1823, 1825, 1826, 1827, 1828, 1829

\section{Archivo Municipal de Sonsonate (Sonsonate, El Salvador)}


Caja Elecciones, 1821-1839. Sonsonate, Libro de Elecciones, 1821-1830.

Caja Elecciones, 1821-1839. Sonsonate, Libro de Elecciones, Elecciones, 1821-1839.

\section{Archivo Municipal de Tegucigalpa (Tegucigalpa, Honduras)}

Tegucigalpa, Libro de Actas, 1845.

\section{Archivo Nacional De Honduras (Tegucigalpa, Honduras)}

Caja 107, No. 3437,ff. 126-127v. (1812). Ayuntamiento de Tegucigalpa, Cuaderno de Actas, Elección, 13 de diciembre.

\section{Constituciones}

Francia. (1791). Constitution française du 3 septembre 1791.

Estados Unidos de América. (1787). The Constitution of the United States.

España (1812). Constitución Política de la Monarquía Española (Constitución de 1812)

Centroamérica, República Federal. (1824). Constitución de las República Federal de Centro-América dada por la Asamblea Nacional Constituyente el 22 de noviembre de 1824

El Salvador, Estado de. (1824). Constitución política del estado del Salvador

Guatemala, Estado de. (1825). Constitución del Estado Político de Guatemala.

Costa Rica, Estado de. (1825). Ley Fundamental del Estado Libre de Costa Rica

Honduras, Estado de. (1825). Constitución del Estado de Honduras.

Nicaragua, Estado de (1826). Constitución del Estado de Nicaragua.

Nicaragua, Estado de (1838). Constitución Política Del Estado De Nicaragua

Honduras, Estado de (1839). Constitución.

El Salvador, Estado de (1841). Constitución.

Costa Rica (1844). Constitución Política Del Estado Libre Y Soberano De Costa Rica 
Guatemala. (1848). Proyecto de Constitución para la República de Guatemala ... (Guatemala: Imprenta de la Paz. (no adoptada)

Honduras (1858[1848]). Constitución política del estado de Honduras decretada por la asamblea constituyente en 4 de febrero de 1848 y reimpresa de orden del gobierno en 1858. Imprenta del Estado.

Alda, S. (2002). La participación indígena en la construcción de la Republica de Guatemala, S XIX. UAM Ediciones.

Alda, S. (2004a). El derecho de elección y de insurrección en Centroamérica: Las revoluciones como medio de garantizar elecciones libres, 1838-1872. En C. Dardé Morales y C. Malamud Rikles (Ed.), Violencia y legitimidad política y revoluciones en España y América Latina, 1840-1910 (pp. 115-142). Cantabria, Universidad de Cantabria.

Alda, S. (2004b). La adaptación histórica de las comunidades indígenas en Guatemala: De cabildos coloniales a municipalidades constitucionales. Bicentenário: revista de história de Chile y América, III (2), 125-152.

Alda, S. y Belaubre, C. (2014). Partido/Facción. En J. Dym y S. Herrera Mena (Ed.), Centroamérica durante las revoluciones atlánticas: el vocabulario político, 1750-1850. IEESFORD Editores.

Annino, A. (1996). The Ballot, Land and Sovereignty: Cádiz and the Origins of Mexican Local Government, 1812-1820". En E. Posada-Carbó (Ed.), Elections before democracy: the history of elections in Europe and Latin America (61-85). Palgrave Macmillan.

Annino, A. (2003). Soberanías en lucha. En A. Annino y F. Guerra (Ed.), Inventando la nación. FCE.

Avendaño, X. (1994). De súbditos a ciudadanos: Las primeras elecciones en la provincia de Guatemala, 1812-1822. Revista de Historia (3-4), 44-54.

Avendaño, X. (1995a). Las características de la ciudadanía en Centroamérica durante el siglo XIX: Estudio de los distritos electorales de Quezaltenango y Granada. Revista de Historia, (5-6), 20-29.

Avendaño, X.(1995b). "Procesos electorales y clase política en la Federación de Centroamérica, 18101840”, PhD diss., Colegio de México.

Avendaño, X. (2007). Elecciones indirectas y disputa del poder en Nicaragua: el lento camino hacia la modernidad. LEA-Grupo Editorial.

Avendaño, X. (2008). Historia electoral en Centroamérica: elecciones, ciudadanía, representación y organizaciones políticas (siglo XIX y XX). Boletín de la AFEHC, (34). http://afehc-historia-centroamericana.org/index.php?action=bul_aff \&id=34.

Avendaño, X. (2014). La institucionalidad jurídico-electoral en Centroamérica durante el siglo XIX: ciudadanía y sufragio. Journal of Iberian and Latin American Research, 20 (1), 19-35, DOI: 10.1080/13260219.2014.888938. 
Barrios, L. (1996). La alcaldía indígena en Guatemala: época colonial (1500-1821). Universidad Landívar, Instituto de Investigaciones Económicas y Sociales.

Bayle, C. (1951). Los Cabildos abiertos en la América hispánica. Boletín de la Academia Nacional de la Historia, 27/25, 575-595.

Belaubre, C. (2011). Le peuple de la ville de Guatemala (1780-1821): gestation et naissance d"une communauté de citoyens". Nuevo Mundo Mundos Nuevos, Debates, (11) [En línea], 2011 URL: http://nuevomundo.revues.org/61186. 10 mayo 2011

Costa Rica. (1886) Colección de leyes, decretos, acuerdos y resoluciones que ha expedido la Legislatura del Estado, desde el día 6 de Setiembre de 1824 hasta el 29 de Diciembre de 1826, $2^{\text {da }}$ ed. Imprenta Nacional.

Chambers, Sarah. (2017). Actoras políticas o ayudantes abnegadas? Repensando las actitudes hacia las mujeres durante las guerras de independencia hispanoamericanas. En (pp.301-331).

Chiaramonte, J. (2004). The Principle of Consent in Latin and Anglo-American Independence. Journal of Latin American Studies, 36 (3), 563-586.

Dardón Flores, R. (2008). Modernidad, voto y representación política en la Patria del criollo: la primera experiencia constitucional en Guatemala. Boletín de la AFEHC, 34. http://afehc-historia-centroamericana.org/index.php?action=fi_aff\&id=1829.

Del Valle, J. C. (1969). El amigo de la Patria Número 2 del 26 de octubre de 1820. Editorial José de Pineda Ibarra.

Demélas-Bohy, M. y Guerra, F. (1996). The Hispanic Revolutions: The Adoption of Modern Forms of Representation in Spain and America (1808-1810). En E. Posada-Carbó (Ed.), Elections before democracy: the history of elections in Europe and Latin America (pp.33-60).

Dym, J. (1997-2006). "Cabildo Database”, base de datos en Filemaker Pro.

Dym, J. (2001). The State, the City and the Priest: Conflict Resolution in Independent Central America, 1821-1840. Comparative urban and community research. En M. Smith y T. Bender (Ed.), City and Nation: rethinking identity and politics (pp. 136-180).Transaction Publishers.

Dym, J. (2005). Ville, Famille et Pouvoir en Amérique Centrale Indépendante, 1821-1850. En M. Bertrand (Ed.), Familles, pouvoirs et institutions, Toulouse (pp. 257-283). Université de ToulouseLe Mirail, Groupe de Recherche sur l'Amérique Latine.

Dym, J. (2006). From Sovereign Villages to National States: City, State and Federation in Central America, 1759-1839. University of New Mexico Press.

Dym, J. (2007). "Conceiving Central America: A Bourbon Public in the Gazeta de Guatemala (17971807)", 99-198. En G. Paquette (Ed.), Enlightened reform in Southern Europe and its Atlantic colonies, c. 1750-1830. Ashgate Press. 
Dym, J. (2008). "Soberanía Transitiva y Adhesión Condicional: Lealtad e Insurrección en el Reino de Guatemala, 1808-1811". En M. Chust (Ed.), 1808: la eclosión juntera en el mundo hispano (105-137). Fondo de Cultura Económica.

Dym, J. (2009) ¿Ciudadano de cual república? Los extranjeros y la construcción de la ciudadanía nacional en Centro-américa, 1823-1845. Itinerarios 3, 11-58.

Dym, J. y Herrera, S. (2014). Centroamérica durante las revoluciones atlánticas: El vocabulario político, 1750-1850. IEESFORD.

El Editor Constitucional. (1821). Guatemala Ciudad.

Estadística de la Ciudad de Sonsonate... Imprenta del Triunfo, 1853.

Esgueva,A. (2006). Las leyes electorales en la historia de Nicaragua. Managua: Editorial El Amanecer.

Falcón, R. (2006). El arte de la petición: rituales de obediencia y negociación, México, segunda mitad del siglo XIX. Hispanic American Historical Review, 86 (3), 467-500.

García, E. (2008). El camino hacia la centralización del poder en Honduras: Una relectura del período conservador (1838-1872). Conferencia llevada a cabo en el XV Congreso Internacional de AHILA, Universiteit, Leiden.

García, J. (1980). La reforma liberal en Guatemala: Vida política y orden constitucional 2da ed. UNAM.

García, J. (1994). Centroamérica en las Cortes de Cádiz. FCE.

Gazeta de Guatemala. (1810). Guatemala Ciudad.

Grandin, G. (1997). The Strange Case of "La Mancha Negra: Maya-State Relations in Nineteenth-Century Guatemala. Hispanic American Historical Review, 77 (2), 211-243.

Guerra, F. (1992). Modernidad e independencias. Ensayos sobre las revoluciones hispánicas. Fondo de Cultura Económica, 1992.

Guerra, F. (1998). De la política antigua a la política moderna. La revolución de la soberanía. En F.-X. Guerra et al. (Ed.), Los espacios públicos en Iberoamérica. FCE.

Gutiérrez, C. (2009). La historiografía contemporánea sobre la independencia en Centroamérica, Nuevo mundo, mundos nuevos. http://nuevomundo.revues.org/54642.

Habermas, J. (1981). Historia y crítica de la opinión pública. Editorial Gustavo Gili, 1981.

Juarros, D. (1981). Compendio de la historia del reino de Guatemala, 1500-1800. Editorial Piedra Santa.

Lehoucq, F. y Molina, I. (2002). Stuffing the Ballot Box: Fraud, Electoral Reform, and Democratization in Costa Rica. Cambridge University Press. 
Luján, J. (1982). La Independencia y la Anexión Centroamericana a México. Serviprensa.

Luján, J. (1989). Los partidos políticos en Guatemala desde la Independencia hasta el fin de la Federación, Anales de la Academia de Geografía e Historia de Guatemala, 23, 29-80.

Manin, B. (1996). Principes du gouvernement représentatif. Flammarion.

Marure, A. (1960) [1837]. Bosquejo Histórico de las revoluciones de Centroamérica. Editorial del Ministerio de Educación Pública.

Meléndez, C. (1993). La independencia de Centroamérica. MAPFRE.

Menendez, I. (1855). Recopilacion de las leyes del Salvador: en Centro-América. Imprenta de L. Luna.

Molina, I. (1991). Costa Rica (1800-1850): el legado colonial y la génesis del capitalismo. Editorial UCR.

Nicaragua. (1867). Recopilación de las leyes, decretos y acuerdos ejecutivos de la republica de Nicaragua en Centro-America... Imprenta del Gobierno.

Obregón, C. (2000). El proceso electoral y el Poder Ejecutivo en Costa Rica. Editorial de la Universidad de Costa Rica.

Pani, E. (2006). 'Ciudadana y muy ciudadana'?: Women and the State in Independent Mexico, 18101830. Gender \& History, 18 (1), 5-19.

Parker, F. (1952). Jose Cecilio del Valle: Scholar and Patriot. The Hispanic American Historical Review, 32 (4), 533-4.

Piccato, P. (2010). Histories of the Public Sphere in Latin America. Graduate Colloquium. Coloquio llevado a cabo en Columbia University, New York. http://www.columbia.edu/ pp143/publicsphereinLA2.pdf.

Pinto, J. (1986). Centroamérica, de la colonia al Estado nacional, 1800-1840. Editorial Universitaria de Guatemala.

Pinto, J. (1997). Reformismo liberal, régimen municipal, ciudadanía y conflicto étnico en Guatemala (1821-1824), CEUR, (32), 4-33.

Posada-Carbó, E. (1996). Elections before Democracy: The History of Elections in Europe and Latin America. MacMillan Press.

Quijada, M. (2005). Las ‘dos tradiciones'. Soberanía popular e imaginarios compartidos en el mundo hispánico en la época de las grandes revoluciones atlánticas. En J. Rodríguez (Ed.), Revolución, independencia y las nuevas naciones de América (pp.61-86). Fundación MAPFRE-Tavera.

Recopilación de las leyes, decretos y acuerdos ejecutivos de la republica de Nicaragua en Centro-América..., Imprenta del Gobierno, 1867. 
Rodríguez, E. (2019). Los estudios de las mujeres y de género en Centroamérica y Chiapasavances y desafíos (1957-2015). Diálogos: Revista electrónica de historia, 20(2), 148-182, DOI $10.15517 /$ dre.v20i2.37161.

Rodríguez, J. (1994). La independencia de la América Española, México. El Colegio de México.

Rodríguez, J. (2015). Political Culture in Spanish America, 1500-1830. University of Nebraska Press.

Rodríguez, M. (1978). The Cádiz Experiment in Central America, 1808 to 1826. The University of California Press.

Sabato, H. (2006). La reacción de América: la construcción de las repúblicas en el siglo XIX. En R. Chartier y A. Feros (Ed.), Europa, América y el mundo: Tiempos históricos. Fundación Rafael del Pino.

Sanders, James E. (2011). The Vanguard of the Atlantic World: Contesting Modernity in Nineteenth-Century Latin America. Latin American Research Review, 46 (2), 104-127.

Santos, J. (2000). Élites, poder local y régimen colonial: el cabildo y los regidores de Santiago de Guatemala, 1700-1787. Plumsock VT, CIRMA, 403-416.

Stoetzer, C. (1979). The Scholastic Roots of the Spanish American Revolutions. Fordham University Press.

Taracena, A. (1995). Periódicos Salvadoreños de la primera mitad del siglo XIX. Fundación Dr. Manuel Gallardo y CEMCA.

Taracena, A. (1997). Invención criolla, sueño ladino, pesadilla indígena: Los Altos de Guatemala: de región a Estado, 1740-1850. Editorial Porvenir/CIRMA.

Valle, R. (1924-1949). La anexión de Centro América a México (documentos y escritos de 1821), 6 vols. Secretaría de Relaciones Exteriores.

Woodward, R. (1965). Economic and Social Origins of the Guatemalan Political Parties (1773-1823). The Hispanic American Historical Review, 45 (4), 561-562.

Woodward, R. (1993). Rafael Carrera and the Emergence of the Republic of Guatemala, 1821-1871. University of Georgia Press.

Woodward, R. (2001). The Formation of Regional Identity in Central America during the First Half-Century of Independence, 1821-1871. Cahiers de l'Université de Perpignan, Arts et Identité Régionale, 32.

Wortman, M. (1982). Government and Society in Central America, 1680-1840. University Press. 